\title{
Analysis of an Intense Winter Extratropical Cyclone that Advanced along the South Coast of Japan
}

\author{
Isao TAKANO \\ Meteorological Research Institute, Tsukuba, Japan \\ (Manuscript received 21 July 2000, in revised form 2 May 2002)
}

\begin{abstract}
A winter extratropical cyclone underwent rapid development along the south coast and east of Japan on 12 February 1994. The evolution and structure of this cyclone were investigated from its formation through the rapid developing stage using subjective surface re-analyses, objective analyses for upper levels, satellite images and other data.

The cyclone formed over eastern China within a broad low-level baroclinic zone. A cold air mass covered the East China Sea and around Japan behind a preceding cyclone, while strong southerly winds brought warm, moist air above and near the incipient cyclone. The surface cyclone progressed eastward over the East China Sea with a moderate deepening rate. It then began developing rapidly south of Japan, over the warm Kuroshio Current. A deep mid-tropospheric trough approached the surface low from northwest and the cyclone extended horizontally as well as vertically. A subtropical jet streak and an associated upper-tropospheric PV anomaly advanced from the rear of the surface low. This cyclone had a cloud system of about $2000 \mathrm{~km}$ scale. Active cloud areas were found mostly to the north and east sides of the surface low.

The incipient cyclone lacked well-defined surface fronts. As it advanced over the East China Sea, frontogenesis proceeded rapidly to form a warm front with appreciable temperature gradient, which extended zonally from the cyclone center. A low-level cold air flow, corresponding to a cold conveyer belt, occupied the northern side of the cyclone. Cold frontgenesis in terms of thermal fields was inactive to the rear of the cyclone center. A strong wind shear line extended in a north-south direction from the low center, between the southerly winds to the east and the westerly winds to the west. The shear line was associated with weak temperature gradient. As the cyclone developed the warm front extended westward relative to the cyclone center to form a bent-back front. The bent-back front was accompanied by significant wind shear between the northeasterlies to the north and westerlies to the south. The frontal system of the developing cyclone thus exhibited a characteristic configuration that differs from the classical conceptual cyclone model.
\end{abstract}

\section{Introduction}

A winter cyclone that advanced along the south coast of Japan on 12 February 1994 produced a record snowfall over the Tokyo

Corresponding author: Isao Takano, Meteorological Research Institute, Tsukuba, Ibaraki, 305-0052, Japan.

Present affiliation: Japan Meteorological Agency. Ote-machi, Tokyo, 100-8122, Japan.

E-mail: itakano@met.kishou.go.jp

(C) 2002, Meteorological Society of Japan metropolitan area. This cyclone was also noteworthy because it underwent rapid development around Japan. In addition, the cyclone was well recorded by the dense observation network with abundant ship reports, from its incipient stage over eastern China to the rapid developing stage south and east of Japan. In cold seasons cyclogenesis frequently occurs in East Asia, and some of these cyclones intensify rapidly over the western North Pacific, in a similar way as over the western North Atlantic. In a statistical analysis of the winter cyclone 
activity over the North Pacific (Gyakum et al. 1989), it was confirmed that most rapid deepening tends to occur to the east of Japan south of $50^{\circ} \mathrm{N}$, in the vicinity of the Kuroshio Current. In winter, cyclogenesis events over the Far East are concentrated into two areas: over the Sea of Japan, and from the East China Sea to the south of Japan (Chen et al. 1991). The cyclogenesis of the present case occurred in the latter area.

There have been several articles concerning the structure and characteristics of extratropical cyclones passing near Japan. It was pointed out that many cyclones near Japan are mediumscale disturbances with a characteristic horizontal scale of $1000 \mathrm{~km}$, and are predominantly low-level systems (Nitta and Yamamoto 1974). They showed that some of the low-level disturbances couple with upper-level troughs to form deep synoptic-scale cyclones. The Air Mass Transformation Experiment (AMTEX'75) provided a unique opportunity for investigations of cyclogenesis and associated air-mass transformation processes through special field observations over the East China Sea. Three cases of winter cyclones during the AMTEX were analyzed, with emphasis on the formation process of the disturbances (Saito 1977). Among them the cyclone of 14 February 1975 developed notably. The surface cyclogenesis occurred over the East China Sea, beneath a preexisting lowlevel cyclonic vortex that had advanced from the China continent. It was noted that the initial cyclone had a low-level warm core structure. The roles of warm advection and diabatic heating effects were discussed as the factors responsible for the cyclogenesis (Saito 1977). The winter cyclone of 14 February 1975 during the AMTEX was also investigated by Chen et al. (1985) and Chang et al. (1987). However, these studies on the AMTEX cyclone were mostly concerned with the synoptic-scale features of the cyclone, rather than the mesoscale structure including the frontal structure. Nuss and Kamikawa (1990) compared an explosive and a nonexplosive cyclone that advanced along the south coast of Japan. They discussed the impact of heat fluxes from the sea surface over the warm Kuroshio region on the development of cyclones. Takayabu (1991) examined the development process of East-Asia cyclones in association with approaching upper-level troughs.
In an effort to interpret the characteristic cloud pattern and the associated vertical motion of extratropical cyclones over Atlantic regions, the air flows within cyclone systems were explored, termed "conveyer belts" (Carlson 1980; Browning 1990). Among the dominant air flows examined are a warm conveyer belt, a cold conveyer belt and a dry intrusion. The distinction of these airflows is important because the configuration of these airflows is closely linked with the frontal structure of a cyclone.

Over the past years a considerable number of field studies on cyclogenesis were carried out over the North Atlantic. The intensive study of extratropical cyclones during the Experiment on Rapidly Intensifying Cyclones over the Atlantic (ERICA) accumulated new knowledge of the structure and the developing mechanism of these cyclones over the western North Atlantic. Specifically, the ERICA IOP4 cyclone attracted extensive attention, because it underwent extremely rapid intensification (Nieman and Shapiro 1993; Reed et al. 1994 and others). Shapiro and Keyser (1990) proposed a conceptual, fourstage model for rapidly developing ocean cyclones. It is noteworthy that the frontal structure of their conceptual cyclone model differs significantly from that of the classical Norwegian school model (Bjerknes and Solberg 1922). Nieman and Shapiro's (1993) analysis of the ERICA IOP 4 storm include characteristic frontal features, such as westward extension of a warm front (bent-back front) and a cold front extending southward from near the cyclone center, nearly at right angles to the warm front. Shapiro and Keyser (1990) named this type of configuration as "frontal T-bone", corresponding to the third stage of their frontal cyclone model. The formation process and the structure of the T-bone cyclone have been discussed extensively from various aspects (e.g., Nakamura and Takayabu 1997; Ogura 2000).

On the other hand, rapidly developing cyclones to the south of Japan and in the western North Pacific have not fully been documented thus far, in particular for their mesoscale aspects and frontal structure. It is an interesting point whether the geographic conditions over East Asia will be reflected in some manner on the structure of the cyclones in this region. The intention of this study is to describe the evolution and detailed structure of a rapidly 
developing cyclone over the Kuroshio Current. The frontal structure of the cyclone is investigated in considerable detail. Low-level airflows around the cyclone and their association with the strong snowfall are also discussed. The scope of this paper covers from the incipient stage to the start of the rapid developing of the cyclone along the south coast of Japan, during which dense observations existed around the cyclone allowing us to make analyses with sufficient accuracy.

This paper is organized as follows. Section 2 illustrates the observations and analysis methods. Section 3 describes the synoptic conditions and the entire evolution of the cyclone. Section 4 describes the structure of the cyclone at four stages of its development. Section 5 describes the cloud system of the cyclone observed by the satellite and radars. Section 6 discusses the mesoscale aspects and the frontal structure of the cyclone. Section 7 discusses isentropic analyses using the output of a routine mesoscale model. Concluding remarks are made in Section 8 .

\section{Observations and analysis method}

The direct measurement data used for the analyses of the cyclone are mostly routine observations over East Asia, which include SYNOP, SHIP, BUOY and TEMP, compiled by the Japan Meteorological Agency (JMA). Descriptions of synoptic-scale conditions over the wide area of Asia and North Pacific are found in the published weather maps by the JMA. Fortunately, detailed analyses of the evolution of the cyclone from the incipient stage (around 0000 UTC 11 February) to the rapid developing stage (after 0000 UTC 12 February) were possible thanks to the densely distributed observations over the area including abundant ship reports at each stage. We made surface subjective reanalyses of the cyclone for 0000 UTC 11 , 1200 UTC 11, 0000 UTC 12 and 0600 UTC 12 February. These reanalyses are intended to capture the mesoscale structure of the surface cyclone, as well as the synoptic-scale features, utilizing available data fully. The surface frontal analyses were basically in accordance with the JMA forecast guideline. Some coastal fronts and weak low-level baroclinic zones which were not accompanied by wind shear are not explicitly expressed by front symbols. The surface

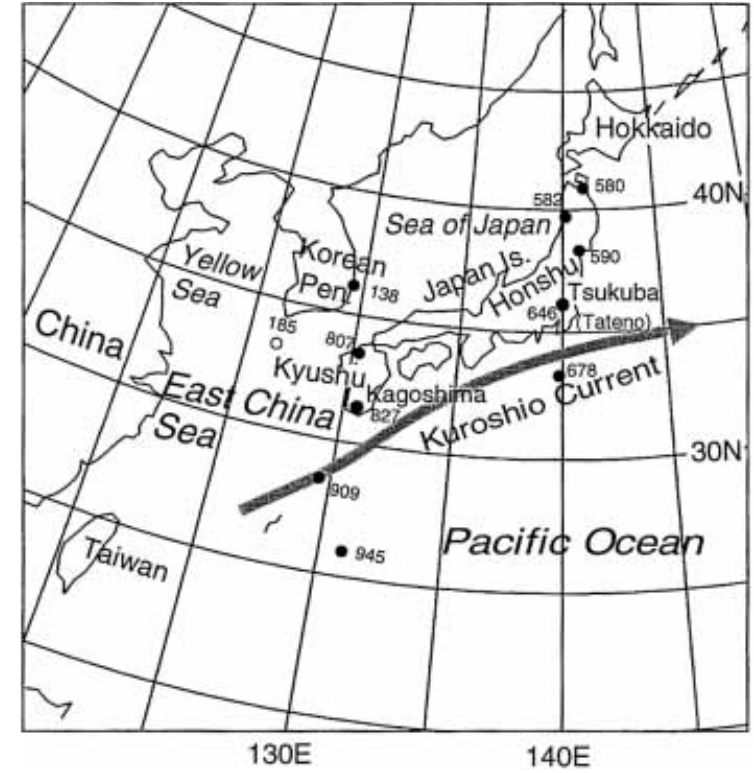

Fig. 1. Topography around Japan. Symbols ( ) indicate the positions of upperair sounding stations used for crosssections along $140^{\circ} \mathrm{E}\left(\mathrm{A}-\mathrm{A}^{\prime}\right)$ and along $130^{\circ} \mathrm{E}\left(\mathrm{B}^{\left.-\mathrm{B}^{\prime}\right)}\right.$ in Fig. 15. The figures represent the last three digits of the station numbers, where the first two digits (47) are omitted.

analyses being produced subjectively, we would not exclude the possibility of other frontal analyses of the cyclone.

In addition to the routine data, extra radiosonde observations were performed at Tsukuba (whose location is shown in Fig. 1) at threehour intervals from 03 UTC 12 to 09 UTC 12 February under the Tsukuba Area Precipitation Studies (TAPS) experiment (Yoshizaki et al. 1999), when the surface cyclone passed about $300 \mathrm{~km}$ to the south. Hourly vertical profiles of horizontal winds were also observed by the $404-\mathrm{MHz}$ profiler at the MRI. The low-level warm frontal zone associated with the cyclone was tilted northward with height. With these additional data at Tsukuba we examined the low-level frontal structure of the cyclone in detail. For a similar purpose, upper-air sounding data at Kagoshima (the location is shown in Fig. 1) near the cyclone center were also studied. The vertical structure of the frontal zones was analyzed through meridional cross-section 
charts composed from the upper-air sounding data.

Horizontal fields of meteorological elements (geopotential height, temperature, dew point depression and wind) at mandatory pressure levels at horizontal $80 \mathrm{~km}$ grid points on polarstereo projection were provided by an objective analysis (JANAL) produced by the JMA. The JANAL mainly covers the Japan Isles and the adjacent water area. An optimum interpolation method was used in the analysis procedure. A forecast-analysis cycle using the Japan Spectral Model (JSM) is employed with a twelvehour update cycle, so that the description of sub-synoptic scale meteorological features are enhanced over data-sparse area. It was confirmed that the JANAL properly represents the structure of the cyclone. We discuss in detail the meteorological features associated with the cyclone expressed in the JANAL at 850 and $500 \mathrm{hPa}$ levels for $0000 \mathrm{UTC}, 1200$ UTC 11 and 0000 UTC 12 February. We also examine the 700 and $300 \mathrm{hPa}$-level JANAL for 0000 UTC 12. On the other hand, the first stage of the low-level disturbance occurred out of the JANAL domain. Thus, the surface and $850 \mathrm{hPa}$ analyses of the JMA at 1200 UTC 10 February 1994, covering a wider area of East Asia than that of JANAL, were used for description of the background of the newly-born disturbance. Additionally, potential vorticity distribution on isentropic surfaces was calculated using the 24 hour forecast of the routine JSM with the initial time at 0000 UTC 11 February.

The Geostationary Meteorological Satellite (GMS) at $140^{\circ} \mathrm{E}$ captured the evolution of the cloud systems of the cyclone from its incipient stage over China to the decaying stage in the Sea of Okhotsk. The original GMS disk images in visible and infrared channels were projected onto polar-stereographic images at the Meteorological Satellite Center, in order to facilitate the comparison with other weather maps. We used the infrared images at 0000 UTC 11,1200 UTC 11, 0000 UTC 12 and 1200 UTC 12 February and the visible images at 0000 UTC, 0300 UTC and 0600 UTC 12 for description of the evolution of the cyclone's entire cloud system. The cyclone produced a record snowfall over the wide area of Japan, in particular along the south coast of Honshu Island, where heavy snowfall is relatively rare. The precipitation intensity obtained by the synthesis of radar reflectivity intensity of the JMA radar network and rain gauge data of the automated surface observations (AMeDAS) was used for analyzing the precipitation pattern of the developing cyclone from 1200 UTC 11 to 0300 UTC 12 February. The estimated precipitation intensity was mostly over land and coastal regions due to the observation range of the radars.

\section{Synoptic conditions of the cyclogenesis}

Figure 2a shows the published surface weather map by the JMA for 1200 UTC 10 February 1994, when the surface low of interest was forming over eastern China. A deep, synoptic cyclone with central pressure of $968 \mathrm{hPa}$ was located to the northeast of northern Japan, which had passed the south coast of Japan on 9 February. After maturing to its final stage of development, this preceding cyclone had an upright structure and was almost stationary for the following two days, when the cyclone under discussion underwent rapid evolution. A highpressure area of $1032 \mathrm{hPa}$ centered in northeastern China at $48^{\circ} \mathrm{N}, 120^{\circ} \mathrm{E}$, expanded to the west of the cyclone, southward as far as near Taiwan.

The $850 \mathrm{hPa}$ temperature analysis by the JMA for 1200 UTC 10 February is illustrated in Fig. 2b. Behind the well-developed cyclone east of Hokkaido, a cold air mass of continental origin spread widely from northern China to Japan. On the other hand, a warm, subtropical air mass advected by southerly winds covered southern China. A broad low-level baroclinic zone extended zonally between the two air masses. At the surface a corresponding stationary front and the associated low-pressure area were analyzed along the low-level baroclinic zone over southern China (Fig. 2a). A low-level cloud area spread near the front, producing moderate precipitation (not shown). In Fig. $2 \mathrm{~b}$ a medium-scale $(\sim 1000 \mathrm{~km})$ low-level cyclonic vortex (whose center is denoted by a black circle) was located over eastern China, within the baroclinic zone.

The cyclone first appeared as closed isobars on the surface weather map of the JMA at 1800 UTC 10 February (not shown) at $29^{\circ} \mathrm{N}, 118^{\circ} \mathrm{E}$, about $300 \mathrm{~km}$ inland from the east coast of China, near the eastern end of the stationary 
(a) Surface

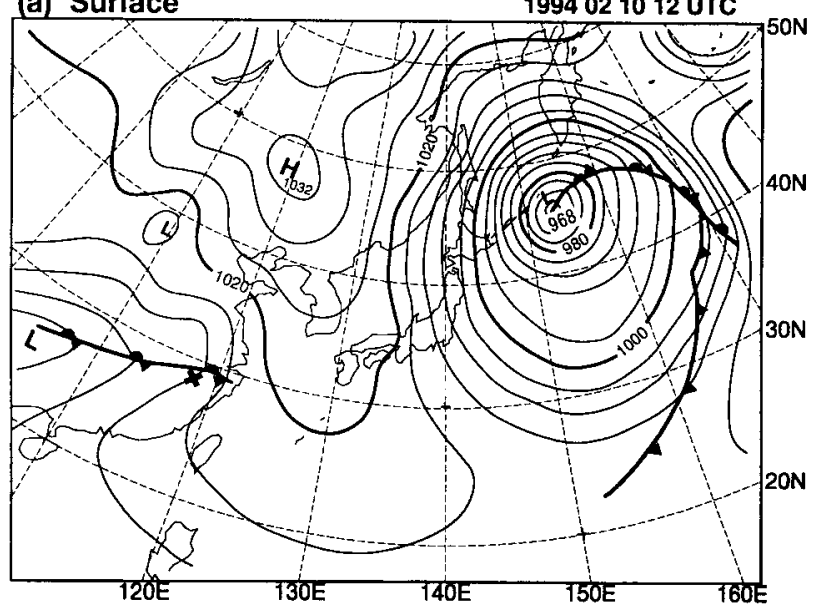

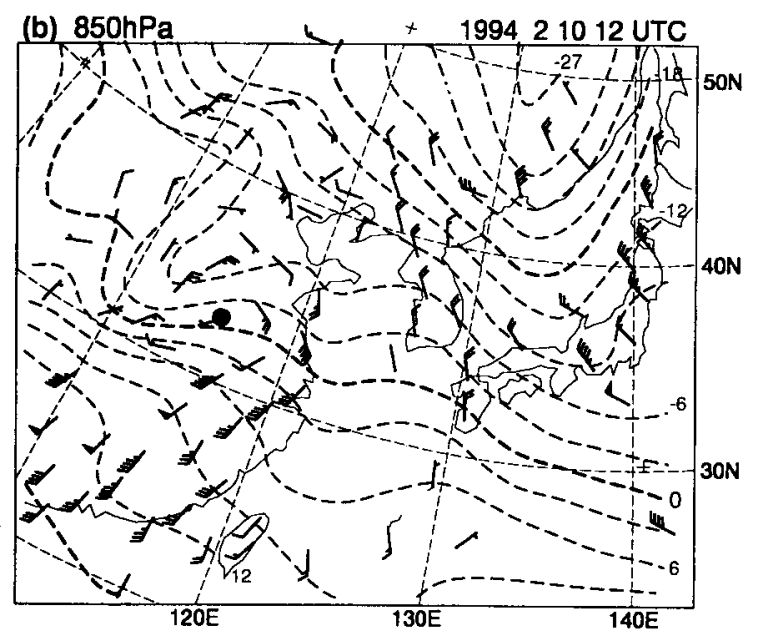

Fig. 2. Weather charts at 1200 UTC 10 February 1994 reproduced from the JMA analyses. (a) Sealevel pressure analysis (solid lines, contour interval is $4 \mathrm{hPa}$ ). The symbol $(\mathrm{x}$ ) denotes the formation position of the surface low at 1800 UTC 10 February 1994. (b) $850 \mathrm{hPa}$ temperature analysis (dashed lines, contour interval is $3^{\circ} \mathrm{C}$ ) and observed winds (a full barb is $5 \mathrm{~m} / \mathrm{s}$ ). The approximate position of the center of the cyclonic circulation of the incipient disturbance is indicated by the $\operatorname{symbol}(\bullet)$.

front (see Fig. 2a). The cyclone formed inland, unlike the AMTEX'75 cyclone that formed over the East China Sea (Saito 1977). A point in common, though, is that the formation of a low-level $(850 \mathrm{hPa})$ cyclonic vortex over the continent preceded the surface low formation. This new-born cyclone progressed slowly eastward. The subsequent track of the surface cyclone within the interval examined in this paper is shown in Fig. 3, together with the objective sea-surface temperature (SST) analysis at $1.0^{\circ} \times 1.0^{\circ}$ degree latitude/longitude grids around Japan. The Kuroshio axis is also superimposed in Fig. 3 as a thick solid line, which was $100-200 \mathrm{~km}$ off the south coasts of Kyushu and Honshu. It should be kept in mind that the temperature gradient of the Kuroshio Current seems underestimated, because of the rather coarse resolution of the SST analysis. At 0000 UTC 11 February the incipient surface low arrived at the east coast of China. The surface low continued eastward progress over the East China Sea, then reached to the west of Kyushu at 1200 UTC 11. The track of the cyclone center crossed the sea surface with strong temperature gradient over the East China Sea to the area with warmer SST of $18^{\circ} \mathrm{C}$ (Fig. 3). After 1200 UTC 11 February the surface cy-

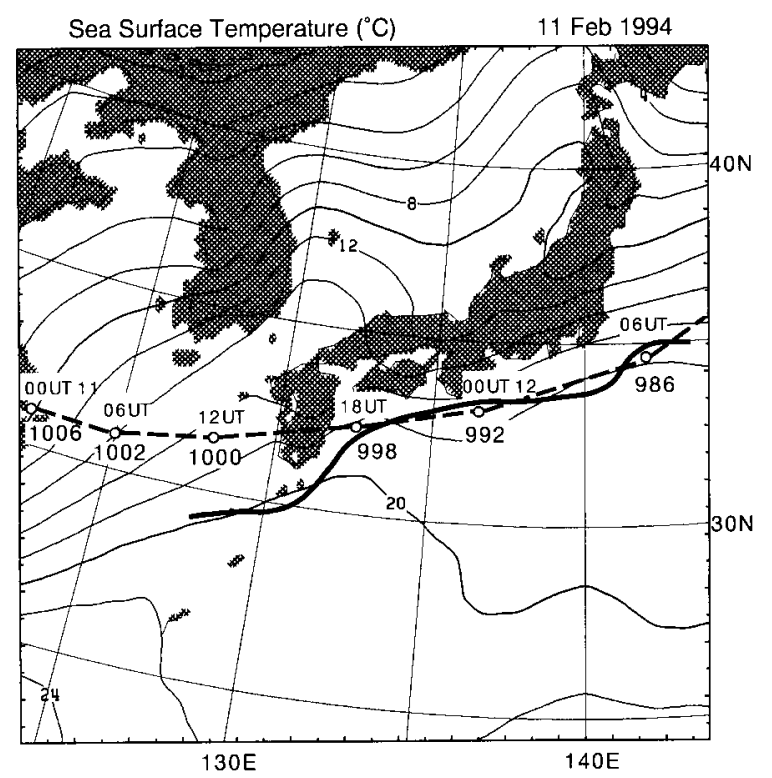

Fig. 3. Track of the surface low between 0000 UTC 11 and 0600 UTC 12 February 1994 (a bold dashed line) and sea surface temperature analysis (contour interval is $2^{\circ} \mathrm{C}$ ) at 1200 UTC 11 February 1994. Six-hourly positions (the symbols, O) and the central sea-level pressure $(\mathrm{hPa})$ of the cyclone are indicated. The position of the Kuroshio Current, taken from a published JMA report, is shown by a thick solid line. 
clone center crossed Kyushu, then progressed ENEastward along the south coasts of the Japan Islands. This path was near the axis of Kuroshio Current, near the SST contour of $18^{\circ} \mathrm{C}$. The cyclone crossed $140^{\circ} \mathrm{E}$ line near 0300 UTC 12, then took more northward course, departing from the Kuroshio Current.

The incipient cyclone at 0000 UTC 11 had a shallow central sea-level pressure of 1006 $\mathrm{hPa}$. The surface cyclone went through moderate deepening of $6 \mathrm{hPa}$ in subsequent 12 hours to $1000 \mathrm{hPa}$ at $1200 \mathrm{UTC} 11$. The cyclone then began rapid intensification, with the surface pressure fall rate comparable to the "bomb" standard of $24 \mathrm{hPa}$ in a day (adjusted to $60^{\circ} \mathrm{N}$, Sanders and Gyakum 1980). At 0000 UTC 12 February the central pressure of the cyclone deepened to $992 \mathrm{hPa}$ south of Honshu. It is notable that the rapid development occurred as the cyclone progressed over the warm Kuroshio Current. During the next 24 hours the surface cyclone continued rapid deepening to $972 \mathrm{hPa}$ at 0000 UTC 13 February as it proceeded northeastward over the western North Pacific. The cyclone recorded the minimum central pressure of $960 \mathrm{hPa}$ at 0000 UTC 14 February to the east of Hokkaido, and then decayed slowly.

\section{The evolution of the frontal cyclone}

\subsection{The incipient cyclone at 0000 UTC 11 February 1994}

A surface subjective reanalysis at this time (Fig. 4a) depicts the incipient cyclone with the shallow central sea-level pressure of $1006 \mathrm{hPa}$ at $31^{\circ} \mathrm{N}, 122^{\circ} \mathrm{E}$, immediately off the east coast of China. The surface low center was situated within a low-level, broad baroclinic zone of moderate meridional temperature gradient. There was a gradual cyclonic wind shift to the east of the surface low center, between the southerly winds to the south and the easterly winds to the north. The surface temperature was much warmer to the east of the cyclone center than to its west, reflecting the low-level warm advection there. The temperature gradient to the east of the low center was intensifying within this confluent wind field. The incipient cyclone, however, lacked a distinct warm front with sharp temperature gradient. The warm-front symbols and dots in Fig. 4a, extending southeastward from the low center, are placed along the wind-shift zone, where the frontogenesis was considered to occur. A conventional cold front was not analyzed behind the cyclone center, in the absence of surface cold advection, whereas the surface stationary front remained over southern China. There was a weak, local baroclinic zone near the south coast of Kyushu as well.

Figure 5a shows the $850 \mathrm{hPa}$ JANAL for temperature and geopotential height at this time. The low-level cyclonic vortex (lowpressure area) had moved slowly eastward to $33^{\circ} \mathrm{N}, 119^{\circ} \mathrm{E}$. It was located about $300 \mathrm{~km}$ to the northwest of the surface low center, indicating the vertical tilt of the low-level cyclone system. A warm, moist airflow with the strong southerlies $(\sim 25 \mathrm{~m} / \mathrm{s})$ blew on the eastern side of the low-pressure area. This way, a sharp thermal ridge was situated above the surface low, along the east coast of China. In contrast, a cold air mass covered Japan, and there was noticeable zonal temperature gradient across the East China Sea. As seen in the surface analysis (Fig. 4a) there was a broad baroclinic zone across the low-level cyclone, and a sharp frontal structure of the cyclone had not yet formed at $850 \mathrm{hPa}$ either.

Figure 6a illustrates the $500 \mathrm{hPa}$ JANAL for geopotential height and temperature. The subtropical jet ran along $30^{\circ} \mathrm{N}$, approximately over the surface low, but its wind speed was not very strong. There was a warm anomaly above the surface low, which was not as significant as observed at $850 \mathrm{hPa}$ (Fig. 5a). A shallow, broad trough on the subtropical jet progressed eastward to $115^{\circ} \mathrm{E}$ (out of the JANAL area), upstream of the low-level cyclone. On the other hand, the main polar front jet ran WNW-ESE, from Siberia to the east of Japan. It is reasonable to consider that the incipient cyclone was predominantly a low-level system.

\subsection{Formation of fronts at 1200 UTC 11 February 1994}

The surface low with central pressure of 1000 $\mathrm{hPa}$ was advancing eastward to reach west of Kyushu $\left(31^{\circ} \mathrm{N}, 128^{\circ} \mathrm{E}\right)$ (Fig. $\left.3,4 \mathrm{~b}\right)$. The cyclone system became organized with packed concentric isobars around the low center, compared to 12 hours before. The pressure gradient around the low center became strong particularly to its northern side, between the cyclone and the high-pressure area to the north. 

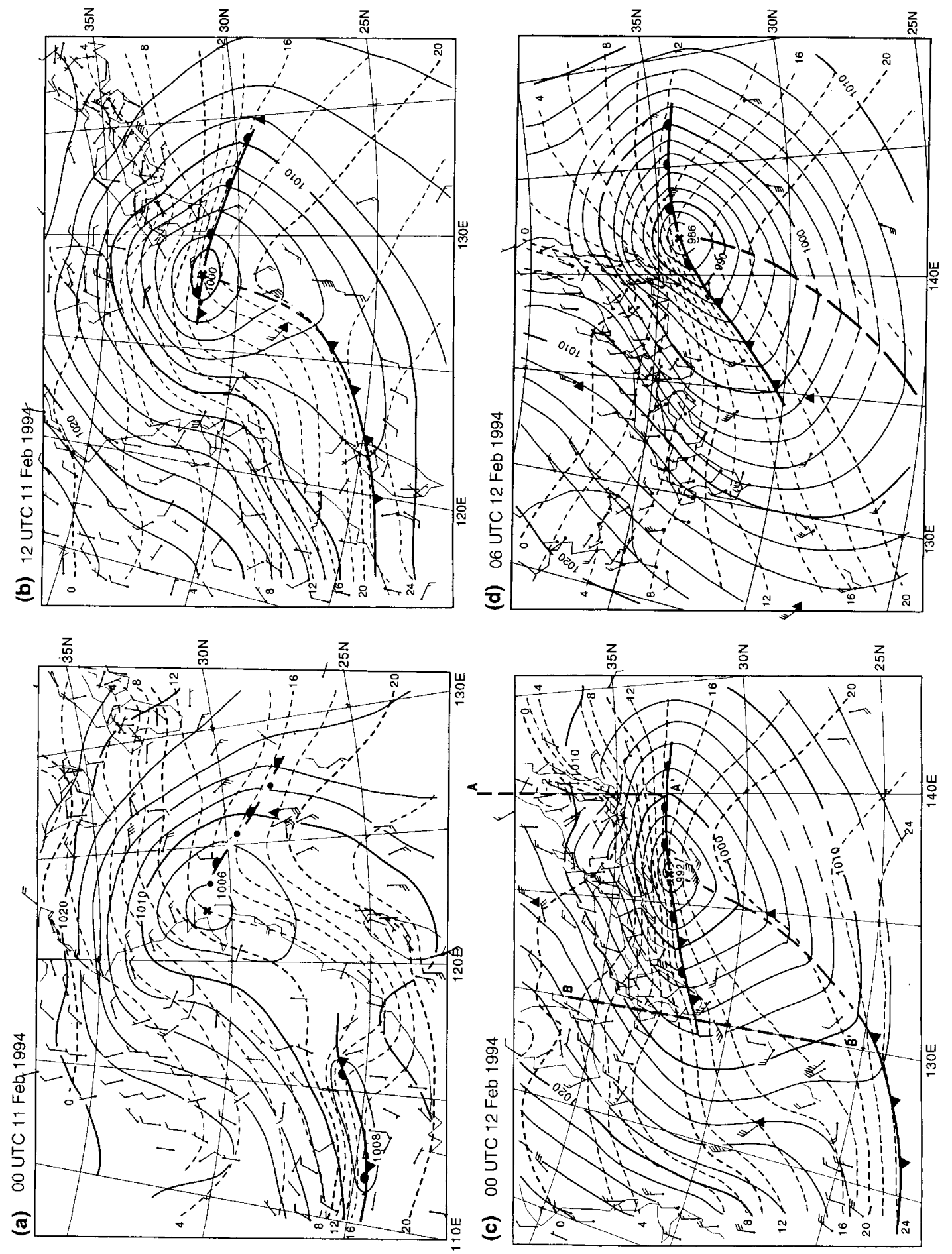

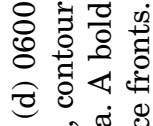

कृ की

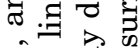

ำ 잉 की

¿

$\circ 0 \%$ 응

(2)

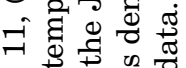

已

مी

옹.己.

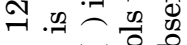

อ त

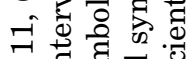

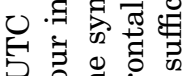

○ 艺

ठㅇㅇㅇ

สิ ฆे छે

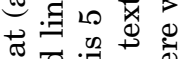

음

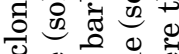

仓寻导弯

o

ఫ0

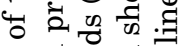

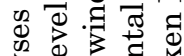

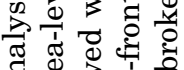

สิ ๗

षं ه

.

远完元

๙

ญ.

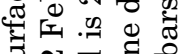

ฟึำ 즈 응

+ن $\dot{\infty}_{1}$ 

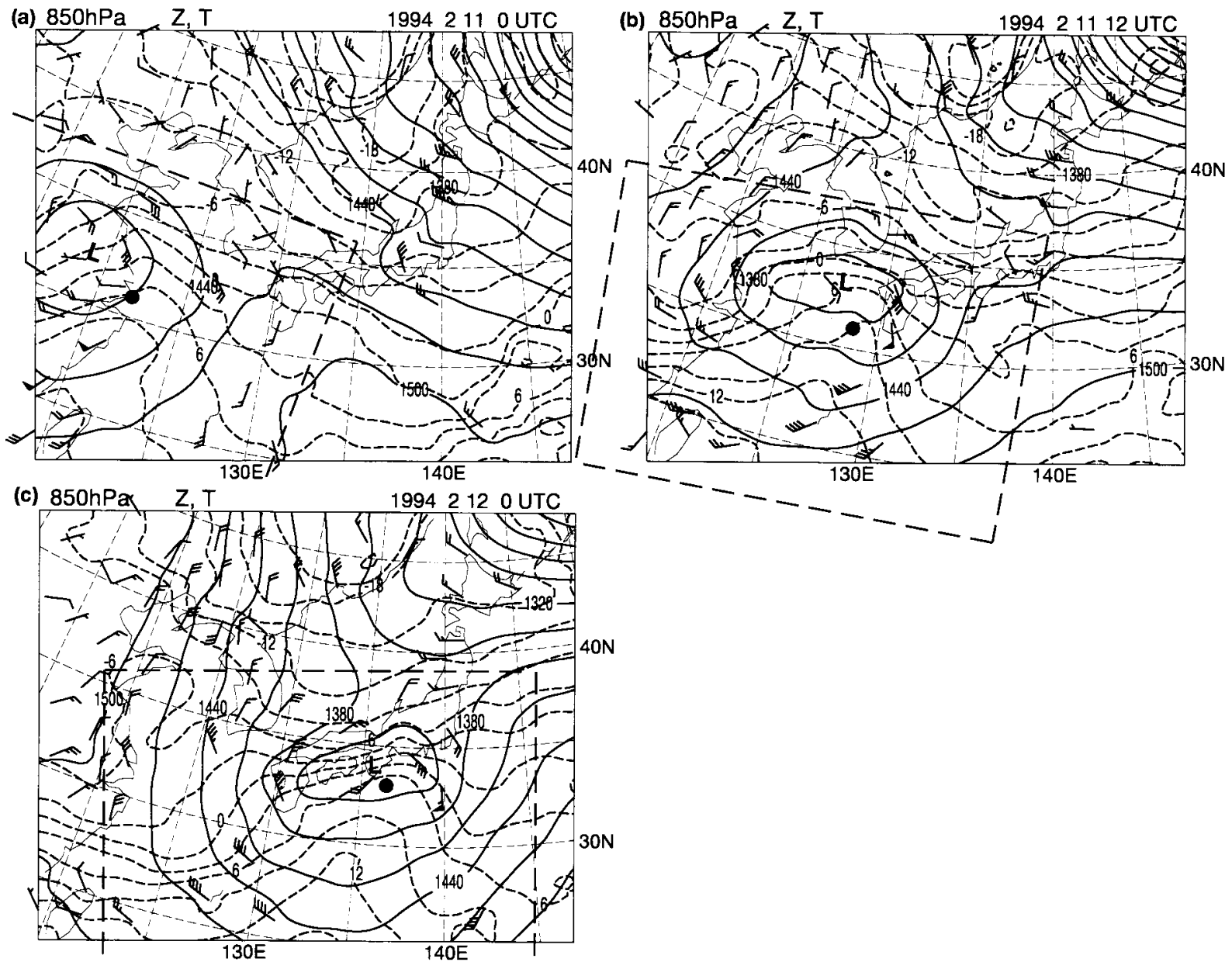

Fig. 5. 850 hPa JANAL at (a) 0000 UTC 11, (b) 1200 UTC 11 and (c) 0000 UTC 12 February 1994. Geopotential height (solid lines, contour interval is $30 \mathrm{gpm}$ ), temperature (dashed lines, contour interval is $3^{\circ} \mathrm{C}$ ) and observed winds (a full barb is $5 \mathrm{~m} / \mathrm{s}$ ) are shown. The symbol ( $)$ denotes the surface low position. The borders of the surface analysis areas of Fig. $4 a-c$ are shown by broken lines.

The surface warm front, which was seen as a broad baroclinic zone 12 hours before, became distinct with increased temperature gradient and wind shift, extending ESE-ward as a narrower zone across the surface low center. Confluence between the easterly winds to the northeast of the low center, and the southeasterly winds to the southeast, appears to have contributed to the rapid frontogenesis. The easterly to northeasterly winds occupied the northern side of the surface low, advecting cold air westward. It seems that low-level frontogenesis started to the rear of the low center as well, with the isotherms aligned mostly in a west-east direction. This part of the front is referred to here as a bent-back front, as in Shapiro and Keyser (1990). A low-level frontal layer corresponding to the bent-back front was observed in an upper-air sounding at Cheju Is. (the station number: 47185 ), $250 \mathrm{~km}$ to the north of the surface front (not shown).

By that time, a new feature, a line of marked cyclonic wind shift became distinct, extending southward from the vicinity of the surface low center, as denoted by a chain line in Fig. 4 b. This wind shear line separates strong southerly winds and northwesterly winds to its eastern and western side, respectively. The wind shear 

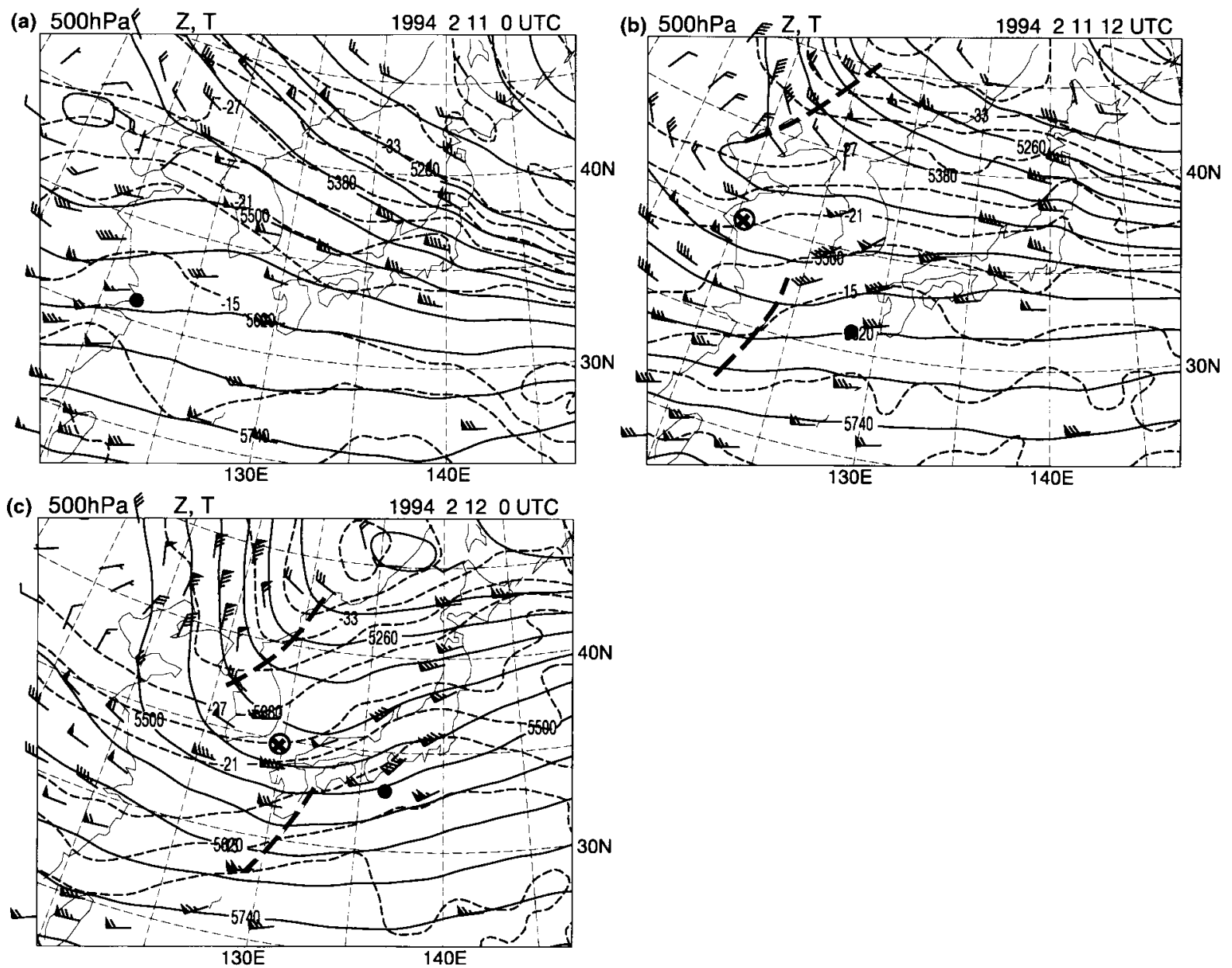

Fig. 6. $500 \mathrm{hPa}$ JANAL at (a) 0000 UTC 11, (b) 1200 UTC 11 and (c) 0000 UTC 12 February 1994. Geopotential height (solid lines, contour interval is $60 \mathrm{gpm}$ ), temperature (dashed lines, contour interval is $3^{\circ} \mathrm{C}$ ) and observed winds (a full barb is $5 \mathrm{~m} / \mathrm{s}$ ) are shown. The symbol $(\bullet)$ denotes the surface low position. The symbol $(x)$ denotes the position of the vorticity center corresponding to the short-wave trough. The thick broken lines indicate the mid-tropospheric trough axes.

line seems to be in contact at near right angles with the warm front to its north. The position of the wind shear line was near the eastern end of a broad, SW-NE oriented baroclinic zone, where northwesterly winds were observed. This wind shear line thus possessed a cold-front-like character, but there was no sign of temperature gradient intensification to form a conventional cold front. We will temporarily refer to this feature as a cold-frontal shear line in this paper.

Additionally, a frontal zone with appreciable temperature gradient and cyclonic wind shear developed southwest of the cyclone, extending mostly zonally. This front slowly moved southward, accompanied by cold advection from the north. It is therefore regarded here as a cold front. The cold front was not in direct contact with the surface low center, unlike that of the classical extratropical cyclone frontal model, but its eastern end seems linked to the coldfrontal shear line.

In order to examine the formation process of the cold front, the surface temperature analysis around southern China at 0600 UTC 11 and the change of surface temperature between 0000 UTC and 0600 UTC 11 are shown in Fig. 7. A frontal zone with intense temperature 


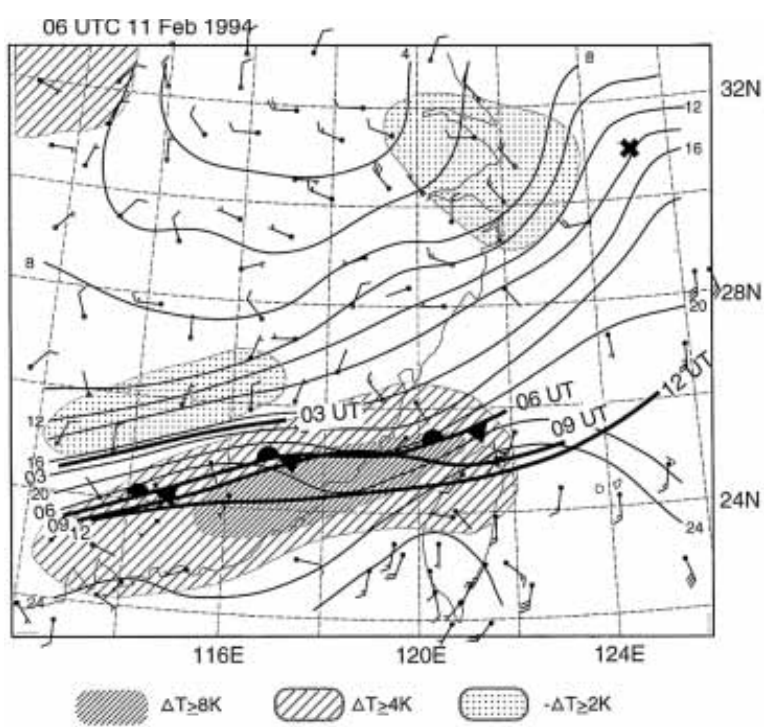

Fig. 7. Surface temperature analysis and observed surface winds (a full barb is $5 \mathrm{~m} / \mathrm{s}$ ) at 0600 UTC 11 February 1994 (solid lines, contour interval is $2^{\circ} \mathrm{C}$ ). Areas with 6 hourly temperature change between 0000 UTC and 0600 UTC larger than $4 \mathrm{~K}, 8 \mathrm{~K}$ and $-2 \mathrm{~K}$ are denoted by different shadings (see Figure). The positions of the surface front at $0300,0600,0900$, and 1200 UTC are shown by bold lines. The position of the surface low at 0600 UTC is indicated by the symbol $(x)$.

gradient extended along $25^{\circ} \mathrm{N}$, where there had been a weak zonal temperature gradient 6 hours before at 0000 UTC (Fig. 4a). The position of the front is an eastward extension of the preexisting stationary front. There was a zonally-extended area of rapid temperature rise $\left(8^{\circ} \mathrm{C}\right.$ in $\left.6 \mathrm{~h}\right)$ immediately to the south of the front. In contrast, there was a narrower zone of slight temperature drop on the northern side of the front. It is readily seen that the intensification and the eastward extension of the front occurred as a result of the differential temperature change, with maximum warming on the southern side of the front, cooling on the northern side. These temperature changes also resulted in the broadening of the frontal zone. The reason for this rapid warming is mostly explainable with strong low-level inflow of warm air, as seen at 0000 UTC 11 at $850 \mathrm{hPa}$ level (Fig. 5a), though the temperature change at the surface lagged behind that at $850 \mathrm{hPa}$. It may not be appropriate until 0600 UTC 11 to regard the front as a cold front, because the temperature rise on the southern side of the front was dominant in the preceding hours. Rather, one may interpret it that the eastern part of the stationary front was intensified by the frontogenetical forcing of the cyclone.

After 0900 UTC the eastern part of the surface front slowly moved southward, extending further eastward, as shown by bold lines in Fig. 7. The northerly winds and a southward expansion of low-level cooler air occurred on the poleward side of the front (not shown). This part of the surface front thus began to behave as a cold front, though the air to the north of the cold front was not very cold, because of the process described above. We see that the formation process of the cold front by 1200 UTC 11 was somewhat different from other cases of typical cold frontogenesis accompanied by a dominant cold air mass behind. The western part of the front in Fig. 7 remained almost stationary.

At this stage the $850 \mathrm{hPa}$ low-pressure area became elongated zonally to take an oval-shape to the northwest of the surface low (Fig. 5b). Similarly to the surface (Fig. 4b), rapid frontogenesis was proceeding, in particular to the north of the low-pressure area, where the isotherms were aligned mostly zonally. The lowlevel easterly winds extended within the frontal zone well behind the surface cyclone center, which seems to account for this temperature pattern. This easterly airflow, prominent below and along the warm frontal zone, corresponds to the cold conveyer belt (Carlson 1980; Browning 1990). The cold frontal zone at $850 \mathrm{hPa}$, which was across Taiwan at surface, extended over the east coast of China, accompanied with northwesterly winds to its rear. It indicates that the cold front inclined backward (northwestward) with height from the surface.

At $500 \mathrm{hPa}$ (Fig. 6b) there was a confluence of jet streams over the East China Sea, where the WNWesterly flow near $35^{\circ} \mathrm{N}$ approached the WSWesterly subtropical jet flow near $30^{\circ} \mathrm{N}$. The shallow mid-tropospheric trough on the subtropical jet was behind the low-level cyclone system. A short-wave trough marked by the relative vorticity maximum, near the southern 
branch of the polar front jet, was advancing eastward over the Yellow Sea, about $800 \mathrm{~km}$ to the WNWest of the surface low. A developing synoptic-scale trough embedded in the main polar front jet entered the JANAL domain from northwest above Siberia, but it was more than $1000 \mathrm{~km}$ apart from the surface low. The midtropospheric troughs, which were at a distance behind the low-level system, were still not very deep. There was no noticeable change in the $500 \mathrm{hPa}$ geopotential height around the surface low from 12 hours before. The middle-level winds over the low-level system changed to WSWesterly, which increased a southerly component.

\subsection{Start of rapid developing at 0000 UTC 12 February 1994}

Figure 4c illustrates the well-developed surface frontal structure of the cyclone, which started rapid intensification off the south coast of Honshu. The central pressure has deepened $6 \mathrm{hPa}$ in 6 hours to $992 \mathrm{hPa}$. The surface winds around the cyclone also intensified, exceeding $20 \mathrm{~m} / \mathrm{s}$ near the low center. It is also noted that the cyclone migrated at an average speed of $19 \mathrm{~m} / \mathrm{s}$, which increased about 50\% from 12 hours before (Fig. 3). The zonally-elongated low pressure area of the surface cyclone became more pronounced. There was strong meridional pressure gradient between the cyclone center and the high-pressure area over the Sea of Japan.

With the approach of the cyclone, heavy snowfall occurred along the south coast of East Japan, which was to the north of the surface warm front. Another factor associated with the intense snowfall was the rapid drop of surface temperature down to near $0^{\circ} \mathrm{C}$ inland. The warm frontal zone had a width of about 150 $\mathrm{km}$, with increased cross-frontal temperature difference. It is remarkable that the bent-back front extended further westward, about $600 \mathrm{~km}$ relative to the low center, along the south coast of West Japan. The bent-back front also went through intensification of wind shift and temperature gradient, where cold easterly to northeasterly winds prevailed to the cold side of the surface front, while westerly winds were strong to the warm side of the front. The observed wind field, involving strong deformation, is considered to promote the frontogenesis.
The cold-frontal shear line extended further southwestward from the cyclone center, between the westerlies to the west and the southwesterlies to the east. The temperature gradient across the shear line became even weaker compared to 12 hours before. The surface cold front, being apart from the cyclone center to the southwest, advanced southeastward. The northwesterly winds became stronger on the cold side of the front, intensifying low-level convergence. Comparing with Fig. 4a one can see that the cyclone experienced rapid frontogenesis within the 24 -hour period. The zonallyelongated shape of the cyclone was also formed within this interval. It is worth mentioning that the analyzed frontal configuration around the cyclone center, consisting of a zonallyextended warm front and a bent-back front, and a meridionally-extended cold-frontal shear line, somewhat resembles the T-bone frontal structure as revealed in the analyses of the ERICA IOP4 storm (Nieman and Shapiro 1993, their Fig. 9). The cold-frontal shear line in this case corresponds to the cold front in Nieman and Shapiro's analysis.

Figure $5 \mathrm{c}$ shows that the $850 \mathrm{hPa}$ lowpressure area was almost in phase with the surface cyclone system, but was displaced northward by $100 \mathrm{~km}$. The cyclone system was located to the southwest of the near-stationary, preceding cyclone northeast of Hokkaido. The warm and bent-back frontal zone at $850 \mathrm{hPa}$ was extended zonally over Honshu, about $150 \mathrm{~km}$ north of the surface front, indicating that the low-level fronts were also inclined northward with height. There was strong cyclonic wind shift across the bent-back front with intensified cold-conveyer-belt airflow to the north, as revealed by the upper-air soundings over Japan.

Figure 8 shows the $700 \mathrm{hPa}$ JANAL equivalent potential temperature $(\theta e)$ and dry areas (T-Td $>10 \mathrm{~K}$, hatched) at 0000 UTC 12 . A band of high $\theta e$ air was advected northward ahead of the low by the southerly winds. The warm frontal zone extended over northern Honshu, which was somewhat diffuse compared to those at the lower levels. The intensified southwesterly winds blew at large angles to the warm frontal zone from the south. One may suppose that the northward airflow then ascended slantwise over the warm frontal zone. 


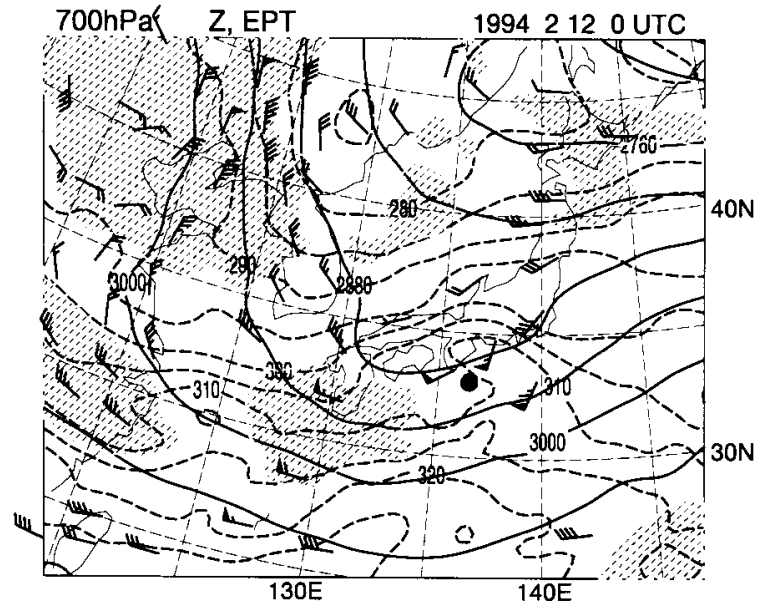

Fig. 8. $700 \mathrm{hPa}$ JANAL at 0000 UTC 12 February 1994. Equivalent potential temperature (dashed lines, contour interval is $5 \mathrm{~K}$ ), geopotential height (solid lines, contour interval is $60 \mathrm{gpm}$ ) and observed winds (a full barb is $5 \mathrm{~m} / \mathrm{s}$ ) are shown. Hatched areas are T-Td $>10 \mathrm{~K}$. The symbol ( ) denotes the surface low position.

This warm airflow was continuous with those observed at lower levels, and conforms to the warm conveyer belt (Carlson 1980). In contrast, dry air areas moved rapidly eastward at the rear of the cyclone, while the corresponding dry air area was well behind the low center at 1200 UTC 11 (not shown). The dry air extended along the warm side of the cold front, which was near $32^{\circ} \mathrm{N}$ west of Kyushu. A wide area of dry air spread over northern China and Siberia as well.

At $500 \mathrm{hPa}$ (Fig. 6c) geopotential height lowered over a wide area to the northwest of the surface low. The synoptic-scale trough accompanied by strong cold advection and marked cyclonic shear advanced southeastward to the east coast of Siberia. This trough later passed over Japan by 0000 UTC 13 from behind the surface low, which underwent rapid deepening. The short-wave trough on the southern branch of the polar front jet, located near the Korean Peninsula (denoted by the symbol $\times$ ), approached the surface low. The mid-tropospheric trough on the subtropical jet stream had progressed eastward to near Kyushu, upstream

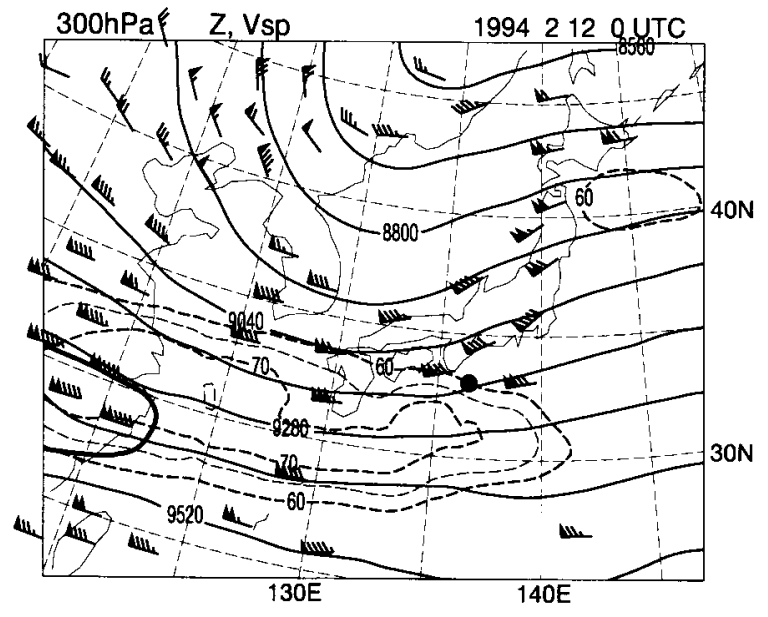

Fig. 9. $300 \mathrm{hPa}$ JANAL at 0000 UTC 12 February 1994. Geopotential height (solid lines, contour interval is $120 \mathrm{gpm}$ ), isotachs larger than $60 \mathrm{~m} / \mathrm{s}$ (dashed lines, contour interval is $5 \mathrm{~m} / \mathrm{s}$ ) and observed winds (a full barb is $5 \mathrm{~m} / \mathrm{s}$ ) are shown. The symbol ( $)$ denotes the surface low position. The $65 \mathrm{~m} / \mathrm{s}$ isotach of the subtropical jet at 1200 UTC 11 is indicated by the thick solid line.

of the surface low, accompanied by intensified wind speed. A broad, deep low-pressure area was established to the northwest of the surface cyclone along $130^{\circ} \mathrm{E}$, with cyclonic vorticity concentrated near the axes of these troughs. It is estimated that the cyclone experienced upperlevel cyclogenetical forcing in front of the deepening trough, where positive-vorticity advection occurred. Another feature to note in Fig. $6 c$ is the intensification of a thermal ridge immediately to the east of the surface low along $140^{\circ} \mathrm{E}$, which was collocated with the southwesterly winds east of the mid-tropospheric trough. A similar middle-level thermal ridge was found in the AMTEX'75 cyclone (Chen et al. 1985). The $500 \mathrm{hPa}$ temperature gradient intensified around the cyclone, however there were no well-defined narrow frontal zones corresponding to those at the lower levels.

Figure 9 shows the isotach and geopotential height contours of the JANAL at $300 \mathrm{hPa}$. This figure shows a deep trough extended from the Sea of Japan to the west of Kyushu, which was almost in phase with the $500 \mathrm{hPa}$ trough (Fig. $6 c)$. A well-defined subtropical jet streak was 
progressing eastward along $30^{\circ} \mathrm{N}$, to the south of the trough. The jet streak had a large wind speed exceeding $70 \mathrm{~m} / \mathrm{s}$. It is important to note that the surface low (Fig. 4c) was at the leftfront exit region of this strong subtropical jet streak. A diffluent wind pattern was also observed there. This configuration is regarded as a favorable condition for the development of cyclones through an indirect vertical circulation at the exit of a jet streak (Uccellini 1990). The jet streak was well behind the surface low by 1200 UTC 11, as shown by a thick solid line in Fig. 9. It is thus suggested that the approach of the jet streak was significant for the start of rapid development.

\subsection{The rapidly developing stage at 0600 UTC 12 February 1994}

After 1200 UTC 12 February surface SYNOP and SHIP data were not densely distributed around the matured cyclone. The scarcity of the surface data does not allow us to make a meaningful reanalysis of the fully-matured cyclone. Instead, we discuss here the reanalysis at 0600 UTC 12 , when there were more surface data available around the rapidly developing cyclone. There are also some uncertainties regarding the position and the intensity of the analyzed wind shear line even in Fig. $4 \mathrm{~d}$ because there were only few ship data to the south of the low.

At 0600 UTC the central pressure of the cyclone was $986 \mathrm{hPa}$ at $34^{\circ} \mathrm{N}, 142^{\circ} \mathrm{E}$ (Fig. $4 \mathrm{~d}$ ), deepening $12 \mathrm{hPa}$ in 12 hours. Note that the time interval between the Fig. $4 \mathrm{c}$ and Fig. $4 \mathrm{~d}$ is six hours, instead of twelve hours as in earlier times. A notable change from 0000 UTC 12 is that a high pressure system centered in northern China built up and expanded eastward, while the low-pressure area of the cyclone that had extended rearward over western Japan retreated. Then, the isobars around Japan became aligned more in the meridional direction to the west of the cyclone, and the surface winds changed to the northerlies from the northeasterlies to the west of the cyclone. The rear parts of the low-pressure area and the bent-back front, which had extended zonally to the west of the low, began to advance southward and to rotate counterclockwise, departing from the coastal region. It is reasonable to consider that the bent-back front possessed a cold-frontal character at this stage. In Fig. $4 d$ it is observed that the surface isotherms within the bent-back frontal zone, which were tightly packed at 0000 UTC (Fig. 4c), became somewhat diffuse except near the cyclone center. This change seems related to a divergent, frontlytic pattern near the front, where there were stronger northerly winds immediately to the rear of the bent-back front than to its further north.

\section{Evolution of the cloud systems of the cyclone observed by the GMS and radars}

Figure 10a-d show the Geostationary Meteorological Satellite (GMS) IR imagery at twelvehour intervals from 0000 UTC 11 to 1200 UTC 12 February, corresponding to the four stages of the cyclone evolution discussed in Section 4 . Figure 11 shows the three-hourly GMS visiblechannel images around the cyclone center from 0000 UTC to 0600 UTC 12 February. In Fig. 12 the precipitation intensity associated with the cyclone at three-hour intervals is displayed, estimated by the synthesis of radar reflectivity and the automated surface observation system of JMA (AMeDAS) from 120011 to 0300 UTC 12 February. The evolution of the cloud systems of the cyclone is described using these figures.

\subsection{UTC 11}

At 0000 UTC 11 February 1994 the GMS imagery (Fig. 10a) shows three organized cloud masses over the East Asian Continent and the East China Sea, hereafter labeled as A, B and C. The cloud mass B, the largest of the three, primarily corresponded to the main body of the incipient cyclone system. The surface cyclone center was located near the center of the leaf-shaped cloud mass B. In the preceding 12 hours, the cloud mass B became organized with increasing cloud-top height, corresponding to the cyclogenesis within the low-level baroclinic zone over China. The southwestern part of the cloud mass B included some convective clouds along the low-level frontal zone (Fig. 4a). The cloud system A appeared to the east of a middle-level short-wave trough, to the northwest of the cloud mass B and the surface low. Embedded within the polar front jet, it was composed mostly of middle- to high-level clouds. The cloud mass $\mathrm{C}$, composed mostly of dense 

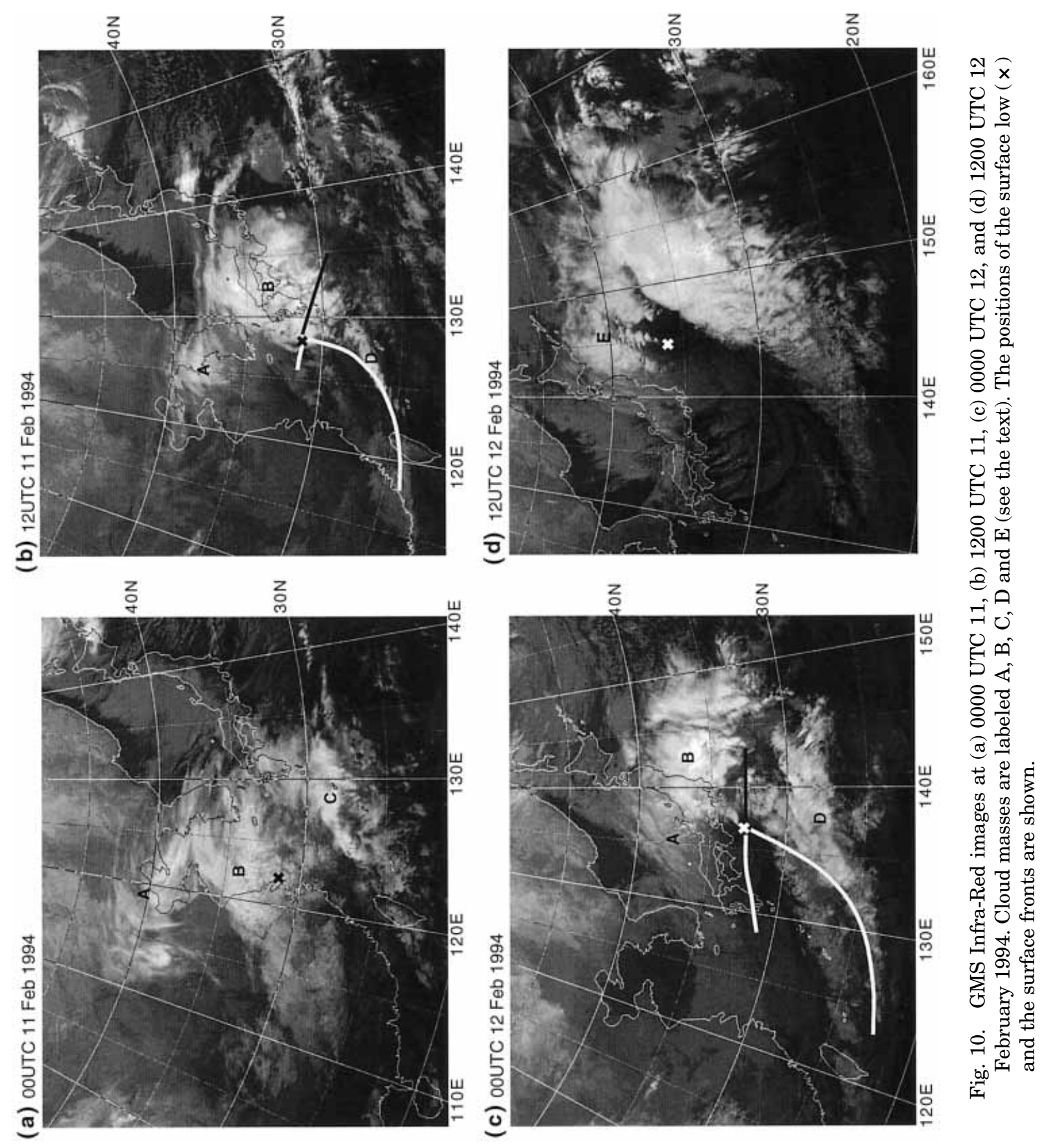


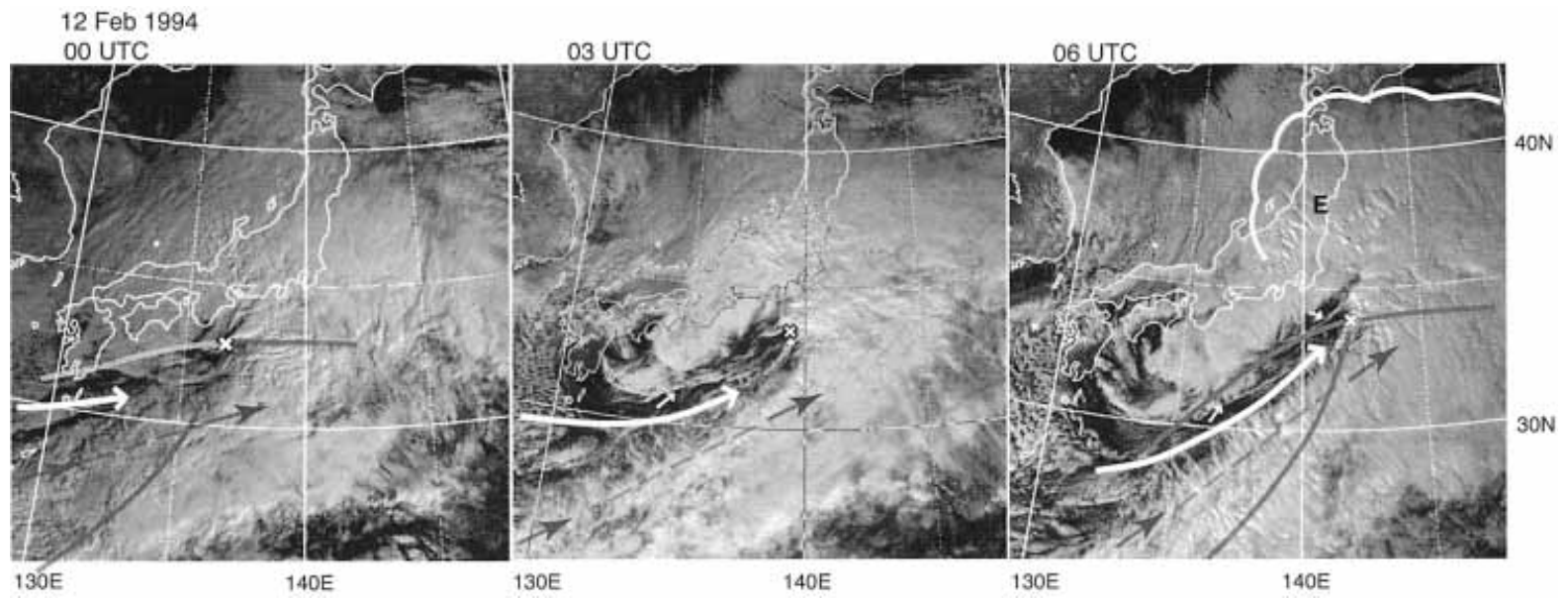

Fig. 11. GMS visible-channel images at 0000, 0300, and 0600 UTC 12 February 1994. The positions of the surface low $(x)$ and the surface fronts are shown. The thick white arrow indicates the dry intrusion. The small arrows indicate the rope clouds. The broken line with arrows indicates the cirrus streak. The outline of the cloud head E at 0600 UTC is drawn by a white line.
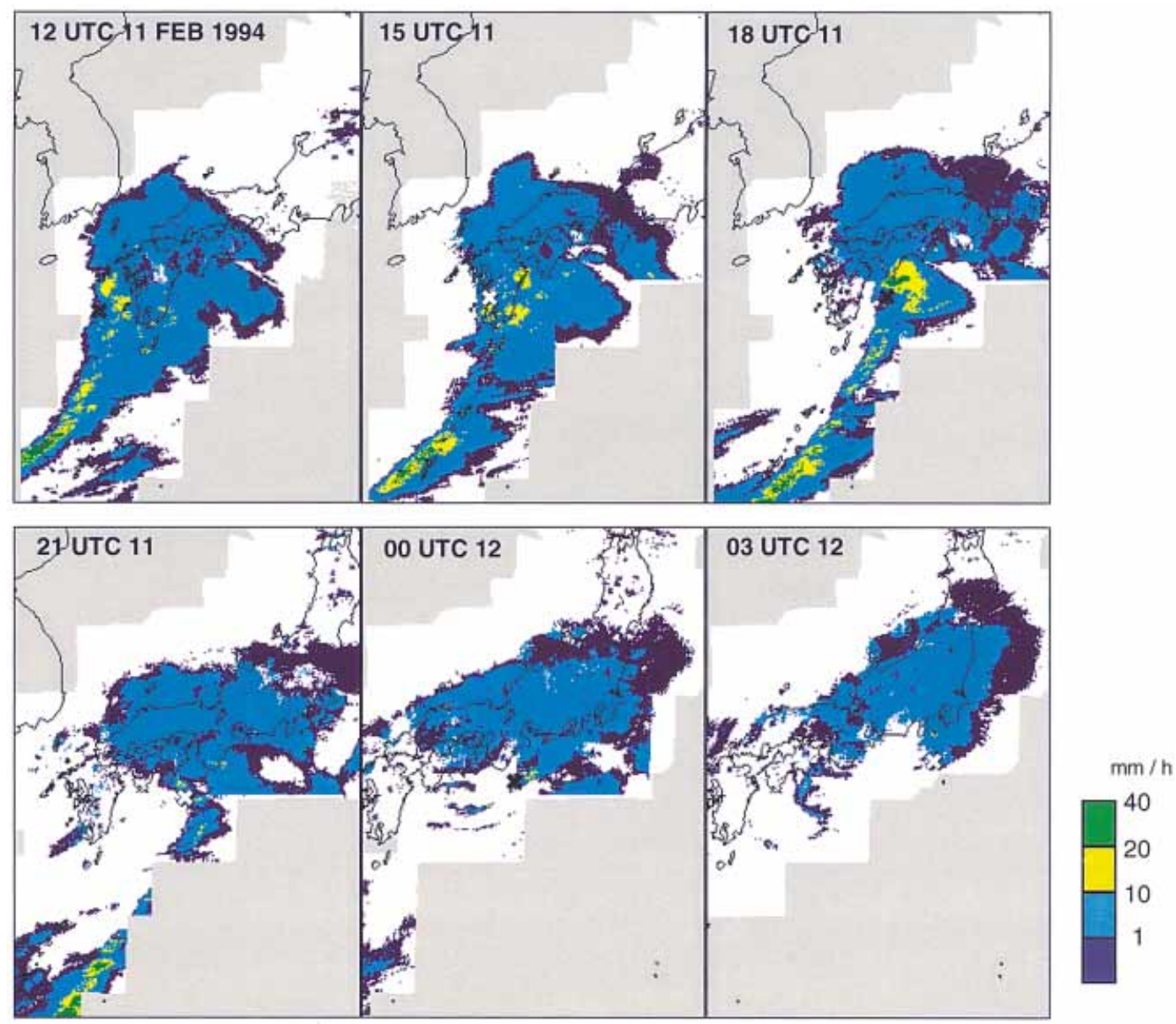

Fig. 12. Three hourly radar-precipitation intensity from 1200 UTC 11 to 0300 UTC 12 February 1994. The positions of the surface low are indicated by the black symbols $(x)$ at 6 -hour interval. The white symbols $(x)$ denote the estimated positions of the surface low at the intermediate times. 
middle-level clouds, was found to the southeast of the surface low. The cloud mass $\mathrm{C}$ continued eastward progress, and became disorganized after 1200 UTC 11 February as it proceeded toward the weak middle-level ridge over Japan.

\subsection{UTC $\sim 1800$ UTC 11}

At 1200 UTC 11 (Fig. 10b) the cloud mass $B$ exhibited a northward bulge, and increased cloud top height. This cloud pattern was associated with the strong northward airflow of the warm conveyer belt. The northward bulge of the dense cloud system is often observed in association with the rapid development of cyclones (Okabayashi 1982). The surface low center gradually shifted toward the western edge of the dense cloud area of the cloud mass B, while low-level stratiform clouds spread west of the low center. The cloud mass A progressed ESEastward, and was located northwest of the cloud mass B.

Figure 12 reveals that active, precipitating clouds were organized as a narrow band near the western end of the cloud mass B after 1200 UTC 11. These active clouds were aligned along the surface cold-frontal shear line (Fig. 4b), where strong low-level convergence was observed. Additionally, a narrow band of mostly convective clouds, about $50 \mathrm{~km}$ in width, (labeled $\mathrm{D}$ ) emerged to the southwest of the surface low center (Fig. 10b). The cloud mass D was a southwestward extension from the active clouds along the cold-frontal shear line, organized along the newly-formed surface cold front (Fig. 4b). The convective clouds formed within the area where the low-level inflow of warm, moist air, and resultant low potential stability condition were maintained (Figs. $4 \mathrm{~b}$, $5 b)$. The precipitation intensity of the cloud band $\mathrm{D}$ of $30 \mathrm{~mm} / \mathrm{h}$ was very strong as a winter phenomenon. In contrast, the cloud area on the northern side of the surface warm and bentback fronts produced weak to moderate precipitation, mostly below $5 \mathrm{~mm} / \mathrm{h}$. After 1500 UTC 11 the western end of the cloud area to the north of the surface low advanced more slowly than the cloud band along the cold-frontal shear line and the surface low itself. This movement led to westward extension of the cloud mass B relative to the low center. It occurred in parallel with the extension of the bent-back front. By 1800 UTC 11 the precipitation intensified fur- ther, in particular in front of the surface low center, where active convection was recognized.

\subsection{UTC 0600 UTC 12}

By 0000 UTC 12 February (Figs. 10c, 12) the cloud mass A merged with the northern part of the cloud mass B. It occurred at the same time as the associated mid-tropospheric trough on the polar front jet approached the subtropical jet and the cyclone system (Fig. 6c). Obana (1982) discussed the evolution of cyclone clouds observed by the GMS over East Asia, stating that a typical case of a developing cyclone occurs as a cloud mass associated with the polarfront jet trough approaches another cloud mass associated with the subtropical jet trough. The merger of the cloud masses $\mathrm{A}$ and $\mathrm{B}$ is consistent with his discussion. This process also seems related to the cyclone development discussed by Takayabu (1991), in which an approach of an upper trough induces the development of a low-level disturbance.

The cloud-top height associated with the cloud mass A lowered from north to south. However, the northern part of the cloud mass A, which was over the Sea of Japan, produced little precipitation (Fig. 12). The low-level clouds remained west of the dense cloud mass $\mathrm{B}$, covering the western part of Japan, while the surface low center progressed rapidly ENEastward. The western part of the cloud mass B included low-level cumulus clouds near the southern edge of the bent-back frontal zone, which appeared dark in the IR image (Fig. 10c). At the same time, the cloud band $\mathrm{D}$ greatly extended its area, developing in front of the surface cold front and the cold-frontal shear line. As seen in Figs. 10c and 11 a narrow cirrus streak appeared on the northern side of the cloud mass $\mathrm{D}$, extending in a WSW-ENE direction near the subtropical jet (Fig. 9).

After 1800 UTC 11 a zonally-extended cloudfree area of $200 \mathrm{~km}$ width gradually spread to the south of the main part of the cloud mass B, advancing eastward and finally reaching the surface cyclone center by 0300 UTC 12 . This cloud-free area was apparently associated with the dry area, as evident in the JANAL (Fig. 8). This feature is referred to as a "dry intrusion" (Browning and Golding 1985; Browning 1990). The zonal extension of the dry intrusion with time is manifested clearly in Fig. 11, which 
reached about $1000 \mathrm{~km}$ at 0600 UTC 12 . A similar feature is often observed near developing lows in satellite imagery around Japan (Okabayashi 1982), although with a smaller horizontal scale in most cases. In Fig. 11 the southern part of the dry intrusion was covered by the dense cirrus streak with characteristic transverse lines.

It is interesting to note that the border between the low-level cloud area to the north and the almost cloud-free area to the south (dry intrusion) agrees well with the surface bent-back front. Some rope clouds, which are often associated with a surface wind shift and a cold-air outflow, were also observed near the frontal border. These reveal that the observed cloud pattern and the airflows within the cyclone were closely associated, where the cold, easterly winds covered the low-level cloud area, while the westerly dry airflow was seen over the cloud-free area.

After 0000 UTC 12 a dense, upper-level cloud area expanded to the north of the surface low (newly labeled E in Figs. 10d and 11), where the eastern part of the cloud mass A merged with the cloud mass B. This feature seems to correspond to a "cloud head", which is often observed in a developing frontal cyclone over North Atlantic (Browning and Roberts 1996). The rear part of this cloud area was at first composed mostly of middle-level stratiform clouds, then began to include convective clouds, as recognized by a rugged pattern in the visible-channel images. The poleward part of the cloud head was primarily associated with the warm conveyer-belt airflow with high $\theta e$ value, which ascended slantwise above the warm frontal zone. The rear part of the cloud head, having a lower altitude, was produced by rearward, slowly ascending cold conveyer-belt airflow. The inland convective clouds may be enhanced by forced ascent of the cold conveyer belt airflow as it climbed over the high-terrain area of central Honshu.

Figure 13 shows a close-up of the precipitation intensity near the cyclone center for 0000 UTC 12 February. Notably, a narrow active convective area with a tapering shape was immediately ahead of the surface low center. Figure 13 illustrates that relatively strong precipitation occurred within a zonally-oriented band of $100 \mathrm{~km}$ width, which was about $200 \mathrm{~km}$

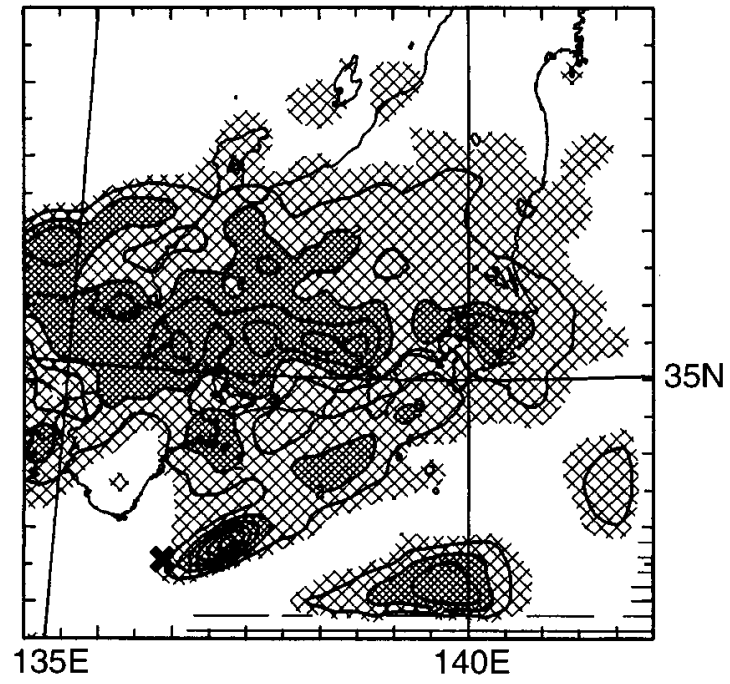

Fig. 13. Radar-AMeDAS precipitation intensity at 0000 UTC 12 February 1994. Contour interval is $1 \mathrm{~mm} / \mathrm{h}$. Light shading and heavy shading indicate precipitation intensity larger than $0.5 \mathrm{~mm} / \mathrm{h}$ and $2.0 \mathrm{~mm} / \mathrm{h}$, respectively. The position of the surface low is indicated by the symbol $(x)$.

to the north of the surface cyclone center. This cloud band, composed mostly of low- and middle-level stratiform clouds, brought heavy snowfall over the wide area of Honshu, along with near freezing-point surface temperature. This band was nearly parallel to the low-level frontal zone, to the north of the surface warm and bent-back fronts (Fig. 4c). It implies that the banded structure of the precipitation clouds was maintained by the cross-frontal vertical circulation.

\subsection{UTC 12}

After 1200 UTC 12 (Fig. 10d) the cloud mass D continued its northward expansion, and merged with the cloud mass $\mathrm{B}$ to form a $2000 \mathrm{~km}$-scale cloud system of a synopticscale cyclone. With the rapid deepening of the surface low and the corresponding midtropospheric trough along $135^{\circ} \mathrm{E}$, the cyclone exhibited a rapid expansion of high cloud area on the eastern side of the surface low. The SWNE oriented high cloud area was roughly parallel to the subtropical jet streak on the eastern side of the trough. The cloud head E also ex- 


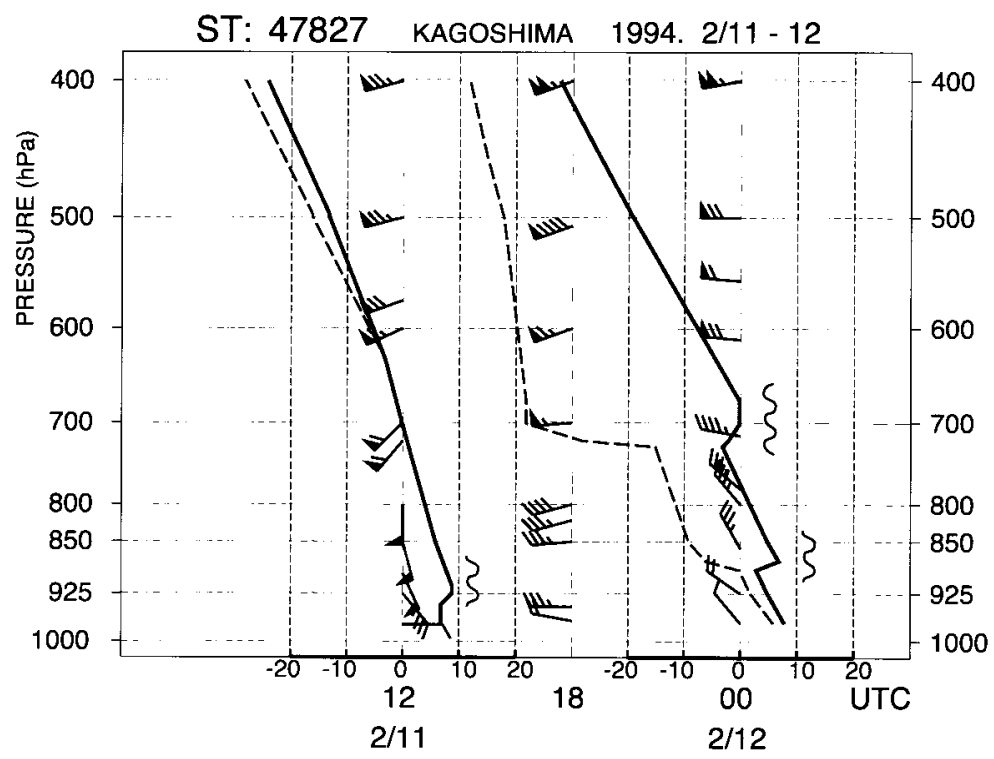

Fig. 14. Upper-air soundings at Kagoshima from 1200 UTC 11 to 0000 UTC 12 February 1994. Temperature (thick solid lines), dew-point (dashed lines) and horizontal wind (a full barb is $5 \mathrm{~m} / \mathrm{s}$ ). The frontal inversions are indicated by wavy lines.

panded its area, and increased cloud-top height. The rear part of the cloud head had cyclonic curvature to the northwest of the surface low with its end extending southward, forming a hook shape. It seems that inflow of upper-level cold air from the northwest, as seen in Fig, 6c, contributed to the intensification of the convective activity within the cloud head.

The low-level cloud area that had occupied the northern side of the bent-back front rotated cyclonically, extending southward to the west of the low center. It suggests that the bent-back cold front extended roughly in a north-south direction. The surface low was located at the northern tip of the cloud-free (dry intrusion) area. Low-level cumulus cloud streets spread over the Sea of Japan and to the south of Honshu, indicating a cold air outbreak behind the cyclone. Unfortunately, we cannot discuss the detailed structure of the cloud system in relation to the frontal structure of the cyclone, because we could not prepare a surface analysis map of the corresponding time.

\section{Mesoscale aspects of the cyclone and the frontal zones}

From the foregoing analyses, such mesoscale features of the developing cyclone, as the cloud- free area (dry intrusion) to the southwest of the cyclone center, the warm and bent-back frontal structure and the cold-frontal shear line were revealed. Here, these features and the characteristic air flows are discussed further through the analyses of the relevant upper-air sounding data.

\subsection{Vertical profile near the low center}

Figure 14 shows the routine upper-air observations at Kagoshima (see Fig. 1) from 1200 UTC 11 to 0000 UTC 12 at six-hour interval. At 1200 UTC 11 February Kagoshima was situated about $200 \mathrm{~km}$ to the east of the cyclone center, and immediately north of the surface warm front (Fig. 4b). The surface low center passed to the north of Kagoshima by 1500 UTC, then at 1800 UTC Kagoshima was about $200 \mathrm{~km}$ behind the wind shear line. At 1200 UTC 11 a warm frontal inversion was below $900 \mathrm{hPa}$, and a deep layer of near-saturated air was observed up to the tropopause. Strong southerly winds $(\sim 25 \mathrm{~m} / \mathrm{s})$ corresponding to the warm conveyer belt were observed near 800 $\mathrm{hPa}$ above the warm frontal zone, veering rapidly with height to WSWesterlies above 600 $\mathrm{hPa}$. These features clearly illustrate a vigorous northward transport of warm, moist air in front 
of the cold-frontal shear line, as already observed in the $700 \mathrm{hPa}$ JANAL (Fig. 8).

Six hours later at 1800 UTC the low-level $(\sim 850 \mathrm{hPa})$ wind changed from southerly to westerly, while at the middle- to upper-levels, the wind directions remained almost unchanged. This low-level wind shift was associated with the passage of the cold-frontal shear line depicted on the surface reanalysis maps (Fig. 4). At 0000 UTC 12 the low-level winds at Kagoshima changed further to northwesterlies from westerlies, as the bent-back front moved southward slowly. A deep layer of extremely dry air ( T-Td $>15 \mathrm{~K}$ ) replaced moist air observed at 1200 UTC 11, except near the surface. Marked inversions were found near $700 \mathrm{hPa}$ and $900 \mathrm{hPa}$, at the bottom of the dry air, suggesting that the dry air mass was associated with subsiding motion. The middle-level winds also changed to westerlies from WSWesterlies, which was associated with the passage of the weak short-wave trough. These indicate that the cold-frontal shear line was near the boundary between the wet air mass of the warm conveyer belt ahead and the dry intrusion air behind. Unfortunately, the six-hourly data by the routine radiosonde observations are too coarse for detecting more precisely the position of the boundary between these air masses.

\subsection{Vertical structure along $140^{\circ} \mathrm{E}$ at 0000 UTC 12}

Figure 15a shows the vertical cross section of potential temperature and observed horizontal winds along $140^{\circ} \mathrm{E}\left(\mathrm{A}-\mathrm{A}^{\prime}\right.$ in Fig. 4c) at 0000 UTC 12 February across the surface warm front, which was constructed from selected upper sounding station data (see Fig. 1 for the locations and the station numbers). In Fig. 15a the warm frontal zone, which was located between Tateno (the station number is 47646) and Hachijo jima (47678) at the surface, was inclined northward with height as far as about $700 \mathrm{~km}$. The warm front extended northward beneath the dense cloud area (Fig. 10c). It is possible to estimate that the warm frontal zone had a depth of $1 \sim 1.5 \mathrm{~km}$, though there is some uncertainty about the shape of the warm front at its southern end, because it was between two stations about $300 \mathrm{~km}$ apart. Figure 15a also shows that the warm front was predominantly a low-level feature, below $600 \mathrm{hPa}$.
To the south of the front, strong southerly winds occupied the low-level layer below 700 $\mathrm{hPa}$, which carried warm moist air northward. With the inflow of high $\theta e$ airmass, the lowlevel layer was nearly in a convectively neutral condition. Southerly winds veered with height to southwesterlies, and increased wind speed to above $50 \mathrm{~m} / \mathrm{s}$ at $500 \mathrm{hPa}$. To the north of the surface front, the wet easterlies were observed at Tateno below the warm frontal zone, corresponding to the cold conveyer belt. The easterly airflow had temperature well below freezing point, which was an important factor controlling locally the precipitation type to snow. The low-level easterly winds were rather a narrow feature, which were not observed at stations farther north. The warm frontal zone at Tateno was characterized by rapid veering with height to southwesterlies above $700 \mathrm{hPa}$, indicating strong warm advection. The near-saturated air was observed throughout the troposphere in the whole cross section, consistent with the dense cloud system that was observed near the warm front in the satellite imagery.

In addition to the warm frontal zone one sees other high-stability layers in Fig. 15a. A shallow layer of coastal frontal zone was found below the warm frontal zone, near $950 \mathrm{hPa}$ at Tateno, which was confined below $200 \mathrm{~km}$ in horizontal scale. A corresponding narrow zone with moderate temperature gradient is seen in the surface analysis in the coastal area (Fig. 4c). A well-defined middle-level frontal zone of about $50 \mathrm{hPa}$ depth is found in Fig. 15a, which was near $700 \mathrm{hPa}$ at Hachijo Jima rising to $500 \mathrm{hPa}$ at Sendai (47590). The frontal zone involved strong vertical wind shear.

The hourly vertical distribution of horizontal winds observed by the MRI wind profiler during the passage of the surface low is shown in Fig. 16. This figure shows that the low-level easterly winds of about $15 \mathrm{~m} / \mathrm{s}$ (cold conveyer belt) was persistent with little change until 0300 UTC 12. There was gradual rise of the low-level easterly airflow from $900 \mathrm{hPa}$ at 2300 UTC 11 to $800 \mathrm{hPa}$ at 0500 UTC 12 . Below the easterly winds, the northerly wind component gradually increased at the lowest level. This change is consistent with intensified northerly winds to the north of the surface bent-back front at 0600 UTC 12 (Fig. 4d). Concurrently, southerly to southwesterly winds intensified 
(a)

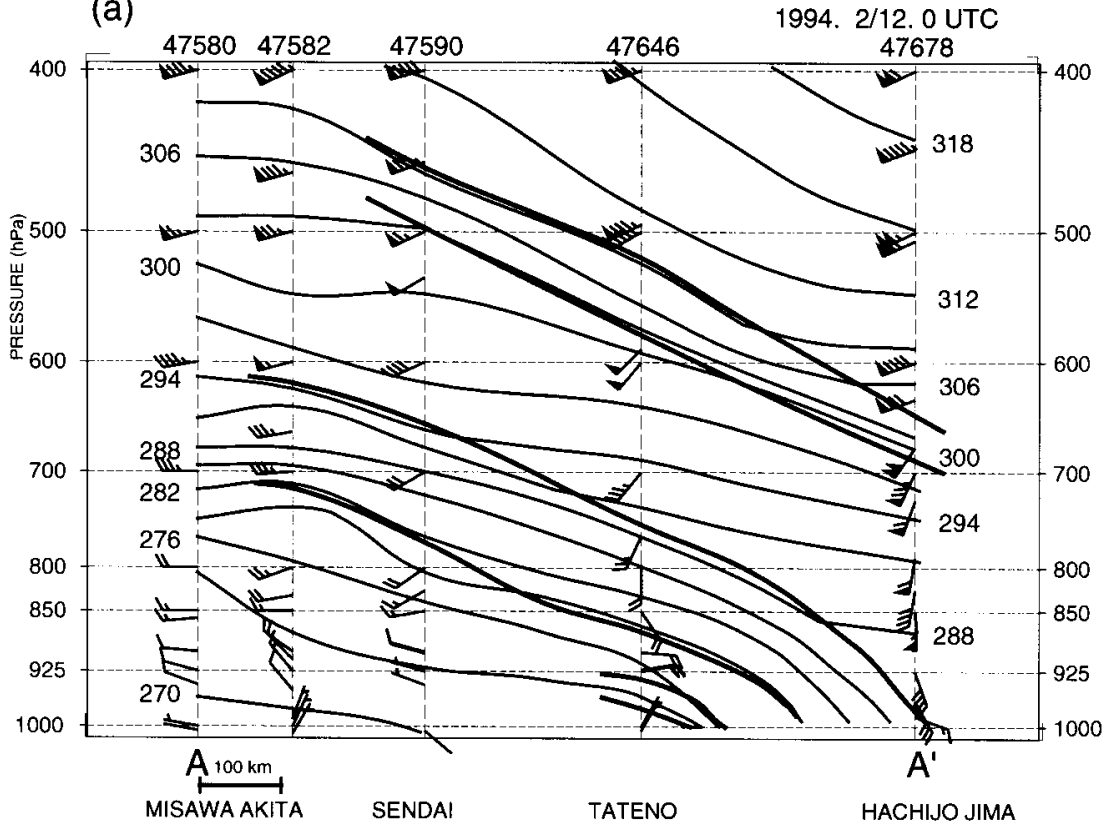

(b)

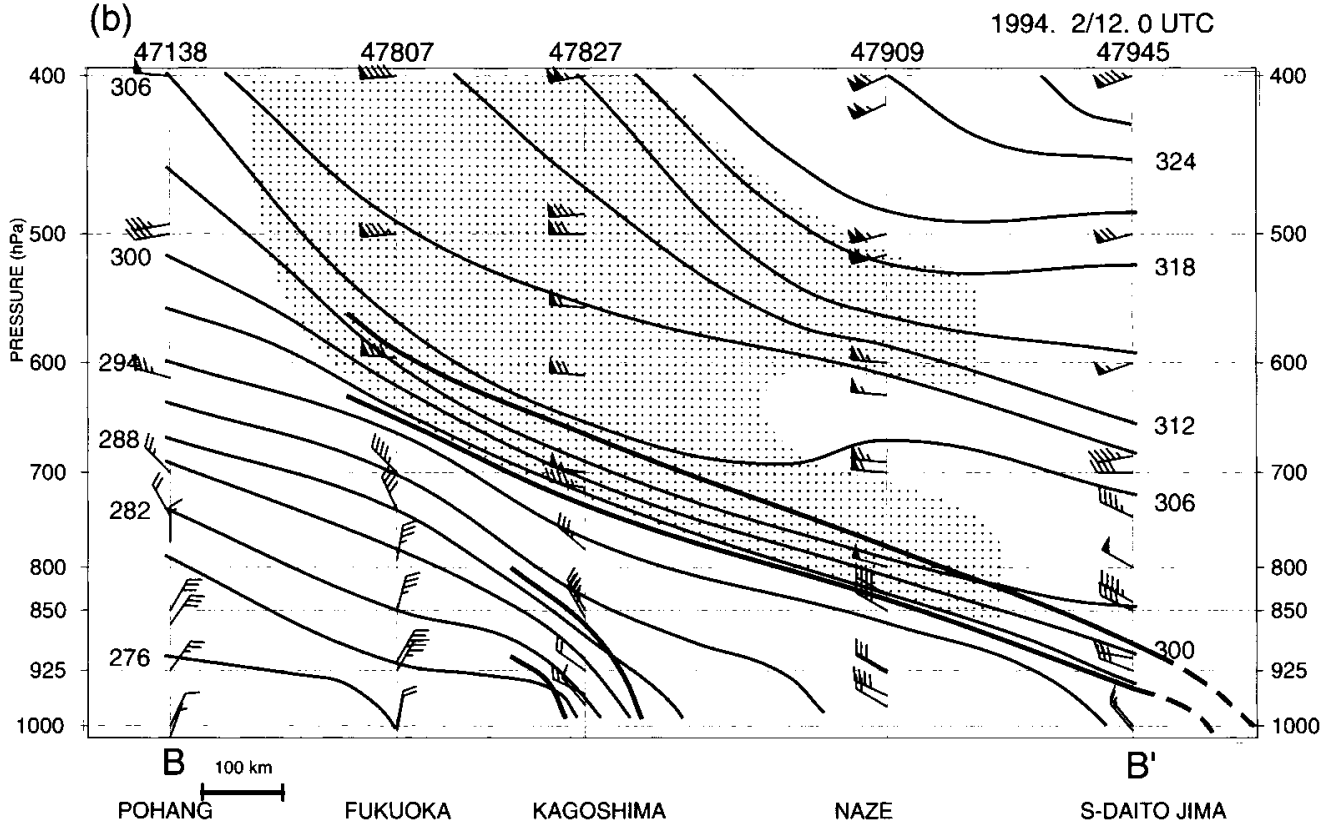

Fig. 15. Vertical cross sections at 0000 UTC 12 February 1994 (a) along $140^{\circ} \mathrm{E}$ (A-A' in Fig. 4c) and (b) along $130^{\circ} \mathrm{E}$ (B-B' in Fig. 4c). Potential temperature (contour interval is $3 \mathrm{~K}$ ) and horizontal winds (a full barb is $5 \mathrm{~m} / \mathrm{s}$ ). The upper and lower boundaries of the frontal zones are indicated by thick lines. In (b) the area with T-Td larger than $15 \mathrm{~K}$ is shaded. There was no dew-point data at S-Daito Jima. See Fig. 1 for the positions of the upper-air sounding stations. The station numbers are shown in the upper part. 


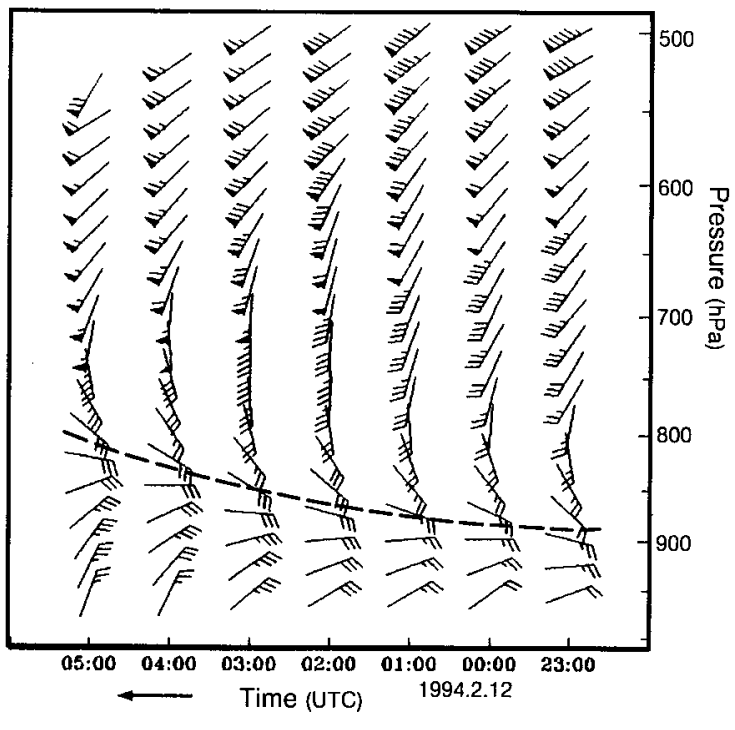

Fig. 16. Hourly time sequence of horizontal winds observed by the MRI profiler from 2300 UTC 11 to 0500 UTC 12 February 1994. A full barb is $5 \mathrm{~m} / \mathrm{s}$. The top of easterly winds is indicated by a dashed line.

near $700 \mathrm{hPa}$, resulting in greater vertical wind shear. The increase of the vertical wind shear was closely correlated with the intensification of the associated bent-back frontal zone.

\subsection{Vertical structure along $130^{\circ} \mathrm{E}$ at 0000 UTC 12}

In Fig. 15b the vertical cross section B-B', along $130^{\circ} \mathrm{E}$ between $36^{\circ} \mathrm{N}$ and $26^{\circ} \mathrm{N}$, at 0000 UTC 12 is illustrated, which runs across the western end of the surface bent-back front, extending southward to the vicinity of the surface cold front (Fig. 4c). The lower part of the subtropical jet streak is recognized by the strong WSWesterly winds at Naze (47909), exceeding $50 \mathrm{~m} / \mathrm{s}$ above $500 \mathrm{hPa}$ level. In Fig. $15 \mathrm{~b}$ the bent-back frontal zone appeared at Kagoshima below $850 \mathrm{hPa}$. The corresponding frontal zone was not evident $200 \mathrm{~km}$ to its north at Fukuoka (47807). It is probably because the cross section was near the western end of the front, where the frontgenesis was considered not significant. The bent-back front was found to have a horizontal scale of at least $400 \mathrm{~km}$ in the eastern side (not shown). The bent-back front at Kagoshima was associated with rapid increase of wind speed with height, mostly northwesterly winds.

The cold frontal zone appeared as a highstability layer of about $50 \mathrm{hPa}$ depth. The front, which was near the right end of the figure at surface, extended as far as $1000 \mathrm{~km}$ to the north. The cold frontal zone was above the bent-back front over Kyushu. The cold frontal zone was also confined below middle level in this figure, as was the warm frontal zone in the cross section A-A'. The frontal zone in Fig. 15b had a relatively small vertical angle of $\sim 1 / 250$, which may be reduced to some extent because the cross section $\mathrm{B}-\mathrm{B}^{\prime}$ intersects the surface front about 30 degrees off normal. WNWesterly winds were observed within the frontal zone, and the wind direction was near perpendicular to the surface front. The vertical wind profile was with backing wind directions with height, implying cold advection. The frontal zone was also characterized by very dry air, where T-Td exceeded $15 \mathrm{~K}$ above the frontal zone. The intermediate layer between the bent-back frontal zone and the cold frontal zone at Kagoshima was also dry (T-Td $\sim 10 \mathrm{~K}$ ), while moist air was below and north of the bent-back front. There was strong cross-frontal vertical wind shear above the cold frontal zone. These features indicate that the front was katabatic, where middle-level air descended along the cold frontal surface. The air mass on the northern side of the cold front had an intermediate value of potential temperature (near $294 \mathrm{~K}$ ) between the warm, subtropical air to the south of the front and the cold air to the north of the bentback front.

\section{Model-aided analyses on isentropic surfaces}

The 24-hour JSM forecast with the initial time at 0000 UTC 11 February 1994 captured the course and the development of the cyclone system with sufficient accuracy. We will use here the output of this forecast in order to supplement the analyses based on observations in the previous sections. The model is a hydrostatic system and has 23 sigma vertical levels and $30 \mathrm{~km}$-horizontal resolution over a $129 \times 129$ grid domain (Segami et al. 1989). The model incorporates full physical processes. The model was initialized from the JANAL. The following isentropic analysis are made 
using the $\sigma$-level forecast results of the JSM in order to discuss the upper-level features associated with the evolution of the cyclone.

\subsection{Isentropic $P V$ analysis on $\theta=320 \mathrm{~K}$}

The impact of an upper-tropospheric potential vorticity (PV) anomaly on surface cyclogenesis was discussed by Hoskins et al. (1985). In this context upper-tropospheric PV defined by $-g\left(\zeta_{\theta}+f\right) /(\partial p / \partial \theta)$ on the $320 \mathrm{~K}$ isentropic surface from 12 hour to 24 hour forecast of JSM is shown in Fig. 17, measured in PVU (1PVU = $10^{-6} \mathrm{~m}^{2} \mathrm{~s}^{-1} \mathrm{Kkg}^{-1}$ ). At 12 hour (valid at 1200 UTC 11) a high PV area spreads to the north of $35^{\circ} \mathrm{N}$ with a maximum exceeding 5 PVU over northeastern China, which corresponds to the synoptic-scale trough (Fig. 6b). At the time the surface low (denoted by the black circle) is located at some distance to the south of the high PV area. At 18 hour (valid at 1800 UTC 11) a narrow band of zonally-extended high PV advances from the continent, which is on the polar side of the upper-tropospheric jet streak (Fig. 9). By 24 hour the high PV anomaly, with a maximum larger than 6 PVU, advances eastward to western Japan, then approaches the surface low, immediately to its north. The westerly winds crosses the PV contours over the East China Sea to western Japan in the down-gradient direction, where positive PV advection occurs.

The simulated PV pattern at 12 hour conforms with the discussion in Section 4 that the cyclone was mostly a low-level disturbance by 1200 UTC 11. The change of the PV observed in Fig. 17 strongly suggests that the vertical coupling of the upper-tropospheric PV anomaly and the low-level disturbance occurred in the start of the rapid development stage of the cyclone around 0000 UTC 12 . The simulated PV anomaly at $24 \mathrm{~h}$ extends almost zonally, unlike the PV pattern of the ERICA IOP 4 case, in which a pronounced cyclonic wrapping of a high PV anomaly area was detected over the surface cyclone (Davis et al. 1996).

\subsection{Isentropic PV analysis on $\theta=295 \mathrm{~K}$}

It is important to understand how the characteristic feature of the cyclone, such as the dry intrusion, formed. Browning (1997) discussed association of a dry intrusion with an uppertropospheric descending motion within a developing cyclone.

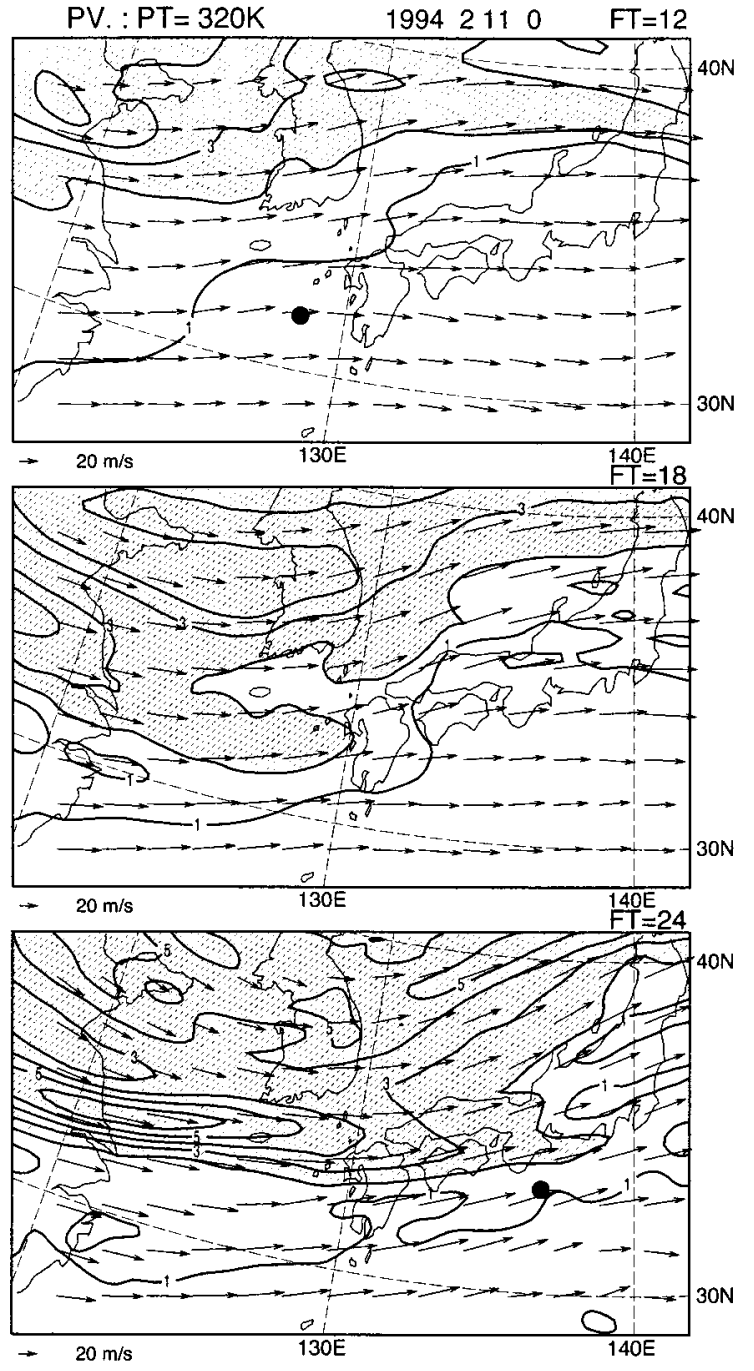

Fig. 17. Potential vorticity on $320 \mathrm{~K}$ isentropic surfaces of the JSM forecast with initial time at 0000 UTC 11 February 1994 at 12, 18, and 24 hour. Contour interval is 1 PVU. Areas with PV larger than 2 PVU are shaded. The symbol (-) denotes the analyzed surface low position in Fig. 4.

Figure 18 shows the positive PV areas (shaded, PV $>1.5$ PVU) and pressure map on the $295 \mathrm{~K}$ isentropic surface of the JSM forecast from 12 hour to 24 hour. The $295 \mathrm{~K}$ isentropic surface is near $550 \mathrm{hPa}$ along the upper end of the figure, and descends to near $900 \mathrm{hPa}$ toward the lower end (equatorward). In the cross section along $130^{\circ} \mathrm{E}$ (Fig. 15b) the $295 \mathrm{~K}$ 


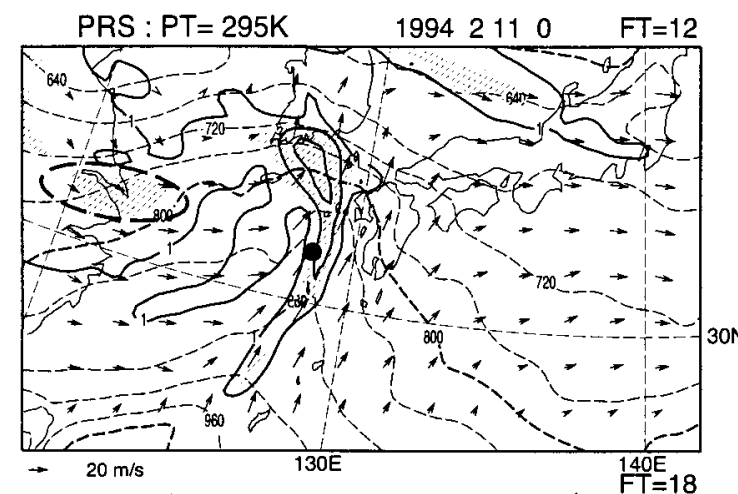

tation areas (not shown), suggesting that the low-level PV anomalies around the cyclone are generated largely by diabatic heating associated with precipitation processes.

At 24 hour (valid at 0000 UTC 12), apart from the PV anomalies around the cyclone, a small patch of relatively large PV (1.5 2 PVU) is situated to the southwest of the cyclone, which is the rear part of the dry intrusion area where precipitation and diabatic heating effects are mostly negligible. It is therefore possible to estimate the movement of the dry-intrusion air using the PV anomaly as a tracer. The PV anomaly can be traced backward 12 hours from $T=24 \mathrm{~h}$ to $T=12 \mathrm{~h}$ to near the east coast of China, which is then to the west of the surface low. Figure 18 shows that the dry air with the PV anomaly moves ESEastward, advected by the WNWesterly winds. It is estimated that the dry air mass descends from $760 \mathrm{hPa}$ to $800 \mathrm{hPa}$ in the 12 hours on the $295 \mathrm{~K}$ isentropic surface. This descending motion is made manifest by the observed low-level inversion at Kagoshima at 0000 UTC 12 (Fig. 14). It was found that the dry air mass does not descend rapidly from upper levels, unlike other case associated with a tropopause fold (Browning 1997). The reason of the relatively high PV value of the dry intrusion air is unclear. The dryness of the tracer air may be attributed to its continental origin.

\section{Concluding remarks}

In this paper we described the time evolution and the structure of an intense winter cyclone that advanced along the south coast of Japan, over the Kuroshio Current at 12 February 1994. The description was based on the 12hourly subjective surface reanalyses, the objective mesoscale analyses (JANAL) at upper levels, the cloud images by the GMS, radars and other observation data including extra radiosonde observations at Tsukuba.

The incipient cyclone formed within a lowlevel, wide baroclinic zone over eastern China, which was a trailing part of a preceding welldeveloped cyclone to the east of northern Japan. The surface low was situated downstream of a shallow mid-tropospheric trough. Until about 24 hours from its formation as a surface low the cyclone initially developed slowly as it crossed the East China Sea toward a warmer SST area (Fig. 3). The cyclone then began developing rap-

isentropic surface was beneath the cold-frontal zone. Positive PV anomalies are found around the cyclone center and along the cold-frontal shear line. These PV anomalies generally extend the areas with time. These PV anomalies roughly agree with the forecast strong precipi- 
idly off the south coast of Japan around 1800 UTC 11. To the south of Japan, the track of the surface low center was near the axis of the warm Kuroshio Current, where there was strong sea surface temperature gradient. With cold air to the north and east of the cyclone and large air-sea temperature difference there, it is considered that a large amount of heat fluxes from the sea surface occurred around the cyclone. The cyclone accelerated ENE-ward remarkably after 1200 UTC 11. After crossing $140^{\circ} \mathrm{E}$ the cyclone changed its course more northward and continued developing, as it departed from the Kuroshio Current. This cyclone track is typical of deepening winter cyclones around Japan (Gyakum et al. 1989).

At $850 \mathrm{hPa}$ the incipient disturbance appeared as a mesoscale circular vortex, located northwest of the surface low. The low-level cyclone then developed a zonally-elongated lowpressure structure as it proceeded over the East China Sea. At 0000 UTC 12 February the $850 \mathrm{hPa}$ low became in phase with the surface low but with a northward tilt. Confluence of the $500 \mathrm{hPa}$ subtropical jet and the southern branch of the polar front jet was seen over the East China Sea, behind the low-level system. With this background, mid-tropospheric disturbances on the two jets advanced toward the surface low, approaching each other. As the cyclone started rapidly developing, a synopticscale mid-tropospheric trough approached the surface low from northwest, accompanied by cold advection to its rear. The cyclone system became tall and tilted westward with height. At 0000 UTC 12 the surface low was positioned at the left-front exit region of a strong uppertropospheric subtropical jet streak, as often reported for explosive cyclones over the North Atlantic (Uccellini 1990). With regard to the development of cyclones, Takayabu (1991) stated that a favorable condition of rapid development is that a low-level vortex is initially located at the latitude of the jet axis, and an upper vortex to the northwest of the lower vortex. This condition seems in general accordance with the situation observed at 1200 UTC 11 and 0000 UTC 12 February in Figs. 5 and 6, where the $500 \mathrm{hPa}$ troughs were found to the northwest of the low-level cyclone below the subtropical jet. It should be kept in mind, though, that the tracks of cyclones discussed in
Takayabu (1991) were mostly near $40^{\circ} \mathrm{N}$, which is north of the cyclone track in this case (Fig. $3)$.

Embedded within a broad low-level baroclinic zone, the incipient cyclone lacked distinct surface fronts (Fig. 4a). The frontogenesis proceeded rapidly within the incipient cyclone to form a low-level warm frontal structure extending ESE-ward from the low center by 1200 UTC 11 (Fig. 4b). The confluence motion in front of the surface cyclone contributed to the warm frontogenesis. With the development of the cyclone, there was rearward extension of the front to form a new feature, a bent-back front. The bent-back front was accompanied by marked wind shear between the northeasterly winds to the north and the westerly to the south, involving strong deformation. By 0000 UTC 12 February (Fig. 4c) the warm front and the bentback front extended zonally to the north of the surface low as a zone with strong temperature gradient, which were also along the elongated central low-pressure area. These fronts were tilted northward with height, and mostly lowlevel features, evident below $600 \mathrm{hPa}$. The cyclone lacked apparent cold frontogenesis adjacent to the surface low. In place of a cold front, a cyclonic wind shear line extended to the south of the low center, between the southerly winds to the east and the westerly winds to the west. No example of such frontal structure as in this case has been reported for other winter cyclones passing south of Japan. It is noteworthy that the frontal configuration of the cyclone at 0000 UTC 12 as a whole resembles the T-bone frontal structure of Shapiro and Keyser's (1990) conceptual model, if one compares the coldfrontal shear line with the cold front of the Atlantic counterpart, for example, Nieman and Shapiro's (1993) analysis of the ERICA IOP 4 cyclone. An important difference is that the cold front of the ERICA IOP 4 cyclone involved intense temperature gradient. The bent-back front was mostly stationary relative to the low center by 0000 UTC 12 . The front later advanced southward counterclockwise with intensified cold advection behind it, thus exhibiting a cold-front-like character (Fig. 4d). After 1200 UTC 11 February a surface cold front with well-defined temperature gradient formed farther rear of the cyclone extending southwestward from the cold-frontal shear line (Fig. 
4b). The cold front was attended by cold advection behind the cyclone, which became apparent after 1200 UTC 11. The frontgenesis was associated with strong low-level convergence, which also led to the formation of an active convective cloud area along the front (Fig. 10b). The cold frontal zone extended northward about $1000 \mathrm{~km}$ with a shallow angle.

The evolution of the cyclone was accompanied by rapid growth of associated cloud systems. In the incipient stage the surface low center was positioned near the center of a large leafshaped cloud mass (labeled B in Fig. 10a) of about $2000 \mathrm{~km}$ scale. By 1200 UTC 11 the northward bulge of the cloud mass $B$ became prominent, indicative of rapid developing, then the surface low center moved to the rear edge of the cloud system (Fig. 10b). A smaller-scale cloud mass A on the polar front jet approached the main body of the cyclone clouds B from northwest. By 0000 UTC 12 the two clouds masses merged over Japan, as the cyclone entered rapid developing stage (Fig. 10c). A dry intrusion, detectable in GMS images as a wedge-shaped cloud-free area, progressed toward the cyclone center from west (Fig. 11). On the other hand, low-level clouds remained to the northwest from the cyclone center with the rearward extension of the bent-back front. Strong precipitation occurred mostly east and north of the low center, along the frontal zones of the cyclone. There was a zonally-extended wide precipitation zone slightly north of the surface warm and bent-back fronts, reflecting active cross-frontal ascending motion (Fig. 13). A convective cloud area in front of the cold-frontal shear line was maintained by low potential stability induced by the inflow of lowlevel high $\theta e$ air there. This feature was similarly observed in the AMTEX'75 cyclone (Chen et al. 1985).

The analyses in the foregoing chapters revealed close association between the frontal structure and the characteristic airflows within the developing cyclone. The strong easterly winds corresponding to the cold conveyer belt persisted to the north of the surface cyclone, beneath the northward-inclined warm frontal zone. A relevant factor was the wide highpressure area spreading to the north of the cyclone, which intensified meridional pressure gradient and hence easterly wind component.
In this manner the moist, cold air mass in front of the cyclone was carried westward to the north of the cyclone, thus enhancing the warm and bent-back fronts. On the other hand, the low-level westerly winds prevailed to the south of the bent-back front, which brought dry, temperate air to the center of the cyclone. The vertical cross section along $130^{\circ} \mathrm{E}$ illustrates a close link between the spreading dry air and the cold frontal zone behind the cyclone (Fig. 15b). Remarkably, the dry intrusion of this cyclone became exceptionally elongated to a $1000 \mathrm{~km}$ length, which is rarely seen within the cyclones over East Asia. The southerly airflow with high $\theta e$ occupied the southeast quadrant of the cyclone from the incipient stage. In the rapid-developing stage the southwesterly winds blew at large angles to the warm front up to $700 \mathrm{hPa}$ (Fig. 8). It shows that the warmconveyer-belt airflow ascended slantwise above the warm frontal zone and the cold air beneath, and this way produced strong precipitation along the low-level frontal zone.

In order to study the processes related to the evolution of the cyclone, potential vorticity distributions on two isentropic surfaces using the JSM output were examined. The PV analysis on $320 \mathrm{~K}$ surface (Fig. 17) showed that a zonally-extended, upper-level high PV anomaly moved eastward and approached the low-level system when the cyclone started rapid deepening. The PV anomaly seems to be closely associated with the subtropical jet streak (Fig. 9). By tracking a weak PV anomaly on $295 \mathrm{~K}$ surface (Fig. 18) it was inferred that the dry intrusion air experienced slow descending motion as it moved east-southeastward from the continent to the rear of the cyclone.

This study covered the evolution of the cyclone from the incipient stage to the start of the rapid developing stage. The structure of the fully-developed stage of the cyclone after 1200 UTC 12 February was not discussed here, because of the lack of observations around the cyclone. Besides, it is not clear at present whether the cyclone with the characteristic frontal structure presented here may be considered as typical of major winter cyclones passing south of Japan. Further studies are needed for analysis of various types of cyclones over East Asia and the western North Pacific, so that a more comprehensive picture of the 
evolution of a typical cyclone in this area can be understood.

\section{Acknowledgments}

The author gratefully acknowledges helpful comments by Dr. S. Yoshizumi regarding several points in the paper. We thank members of the Forecast Research Department of the MRI for their valuable comments and discussions. The author is also grateful to the anonymous reviewers for providing valuable comments, which helped improving the manuscript. The GMS imagery was processed at the Meteorological Satellite Center. The JANAL and JSM data were provided by the Numerical Prediction Division, JMA. The extra radiosonde data and the profiler data were collected under the TAPS (Tsukuba Area Precipitation Studies) collaboration.

\section{References}

Bjerknes, J. and H. Solberg, 1922: Life cycle of cyclones and the polar front theory of atmospheric circulation, Geofys. Publ., 3(1), 1-18.

Browning, K.A., 1990: Organization of clouds and precipitation in extratropical cyclones. Extratropical cyclones. The Erik Palmen Memorial Volume, Amer. Meteor. Soc., 129-153. and B.W. Golding, 1995: Mesoscale aspects of a dry intrusion within a vigorous cyclone. Quart. J. Roy. Meteor. Soc., 121, 463-493.

and N.M. Roberts, 1996: Variation of frontal and precipitation structure along a cold front. Quart. J. Roy. Meteor. Soc., 122, 18451872.

_ 1997: The dry intrusion perspective of extratropical cyclone development. Meteor. Appl., 4, $317-324$.

Carlson, T.N., 1980: Airflow through midlatitude cyclones and the comma cloud pattern. Mon. Wea. Rev., 108, 1498-1509.

Chang, C.-B., D.J. Perkey and W.-D. Chen, 1987: Observed dynamic structure of an intense oceanic cyclone. Mon. Wea. Rev., 115, 11271139.

Chen, T.-C., C.-B. Chang and D.J. Perkey, 1985: Synoptic study of a medium-scale oceanic cyclone during AMTEX'75. Mon. Wea. Rev., 113, 349-361.

Chen, S.-J., Y.-H. Kuo, P.-Z. Zhang and Q.-F. Bai, 1991: Synoptic climatology of cyclogenesis over East Asia, 1958-1987. Mon. Wea. Rev., 119, 1407-1418.
Davis, C.A., E.D. Grell and M.A. Shapiro, 1996: The balanced dynamical nature of a rapidly intensifying oceanic cyclone. Mon. Wea. Rev., 124, $3-26$.

Gyakum, J.R., J.R. Anderson, R.H. Grumm and E.L. Gruner, 1989: North Pacific cold-season surface cyclone activity: 1975-1983, Mon. Wea. Rev., 117, 1141-1155.

Hoskins, B.J., D.J. McIntyre and A.W. Robertson, 1985: On the use and significance of isentropic potential vorticity maps. Quart. J. Roy. Meteor. Soc., 111, 877-946.

Nakamura, H. and I. Takayabu, 1997: Shapiro's new model of frontal cyclones. Tenki, 44, 85-100 (in Japanese).

Nieman, P.J. and M.A. Shapiro, 1993: The life cycle of an extratropical marine cyclone. Part 1. Frontal-cyclone evolution and thermodynamic air-sea interaction. Mon. Wea. Rev., 121, 21532176.

Nitta, T. and J. Yamamoto, 1974: On the observational characteristics of intermediate scale disturbances generated near Japan and the vicinity. J. Meteor. Soc. Japan, 52, 11-31.

Nuss, W.A. and S.I. Kamikawa, 1990: Dynamics and boundary layer processes in two Asian cyclones. Mon. Wea. Rev., 118, 755-771.

Obana, R. 1982: Middle-latitude disturbances observed by the GMS. Meteor. Res. Notes, 145, 89-132 (in Japanese).

Ogura, Y., 2000: An introduction to synoptic-dynamic meteorology. Univ. of Tokyo Press, 289pp, (in Japanese).

Okabayashi, T., 1982: The use of meteorological satellite data (2). J. Meteor. Res., 49, 185-250 (in Japanese).

Reed, R.J., Y-H. Kuo and S. Low-Nam, 1994: An adiabatic simulation of the ERICA IOP 4 storm: an example of quasi-ideal frontal cyclone development. Mon. Wea. Rev., 122, 26882708.

Saito, N, 1977: On the structure of medium-scale depressions over the East China Sea during AMTEX'75. J. Meteor. Soc. Japan, 55, 286300.

Sanders, F. and J.R. Gyakum, 1980: Synopticdynamic climatology of the "bomb". Mon. Wea. Rev., 108. 1589-1606.

Segami, A., K. Kurihara, H. Nakamura, M. Ueno, I. Takano and Y. Tatsumi, 1989: Operational mesoscale weather prediction with Japan Spectral Model. J. Meteor. Soc. Japan, 67, 907-924.

Shapiro, M.A. and D. Keyser, 1990: Fronts, jet streams, and the tropopause. Extratropical cyclones. The Erik Palmen Memorial Volume, Amer. Meteor. Soc., 167-191. 
Takayabu, I., 1991: "Coupling development": an efficient mechanism for the development of extratropical cyclones. J. Meteor. Soc. Japan, 69, 609-628.

Uccellini, L.C., 1990: Processes contributing to the rapid development of extratropical cyclones.
The Erik Palmen Memorial Volume, Amer. Meteor. Soc., 81-105.

Yoshizaki, M., H. Nakamura and K. Nakamura, ed., 1999: Tsukuba Area Precipitation Studies. $M e-$ teor. Res. Notes, 193 (in Japanese). 